\title{
Produção e qualidade fisiológica de sementes de linhagem de milho em função de doses de nitrogênio e umidade na colheita
}

\author{
Production and physiological quality of corn lineage seeds as a function of nitrogen doses and \\ moisture at harvest time \\ Producción y calidad fisiológica de semillas de linaje de maíz em función de las dosis de nitrógeno y \\ la humedad em la cosecha
}

\author{
Thâmara de Mendonça Guedes \\ ORCID: https://orcid.org/0000-0003-1060-4476 \\ Instituto Federal de Educação, Ciência e Tecnologia Goiano, Brasil \\ E-mail: guedes428@gmail.com \\ Hyrandir Cabral de Melo \\ ORCID: https://orcid.org/0000-0001-9546-2539 \\ Universidade Federal de Goiás, Brasil \\ E-mail: hyrandir@yahoo.com.br \\ Cássio da Silva Kran \\ ORCID: https://orcid.org/0000-0001-5084-5034 \\ Instituto Federal de Educação, Ciência e Tecnologia Goiano, Brasil \\ E-mail: cassiosilvakran@gmail.com \\ Luís Sérgio Rodrigues Vale \\ ORCID: https://orcid.org/0000-0002-6303-9063 \\ Instituto Federal de Educação, Ciência e Tecnologia Goiano, Brasil \\ E-mail: luis.sergio@ifgoiano.edu.br \\ Wanderson Moreira dos Santos \\ ORCID: https://orcid.org/0000-0003-1036-1945 \\ Instituto Federal de Educação, Ciência e Tecnologia Goiano, Brasil \\ E-mail: agro.wandsantos@gmail.com \\ Eliaby José de Oliveira \\ ORCID: https://orcid.org/0000-0002-8081-8165 \\ Instituto Federal de Educação, Ciência e Tecnologia Goiano, Brasil \\ E-mail: ejosedeoliveira@gmail.com
}

\begin{abstract}
Resumo
Para a obtenção de híbridos, um estudo inicial feito em linhagens de milho é primordial. Na seleção das linhagens, são observados diversos parâmetros para se chegar ao cruzamento e comercialização. Para aumentar a produtividade do milho, alguns autores afirmam ser necessária uma adubação nitrogenada adequada, sendo o $\mathrm{N}$ o macronutriente mais requerido pela cultura. Desempenha várias funções metabólicos nas sementes, contribuindo para sua formação e para sua reserva nutricional. Este trabalho teve como objetivo avaliar a produção e a qualidade de sementes de linhagem de milho irrigado em função de doses de nitrogênio e graus de umidade na colheita. $\mathrm{O}$ experimento foi conduzido na área experimental do IF Goiano - Campus Ceres e no LAS. Utilizou-se o delineamento experimental em blocos casualizados, sendo cinco doses de nitrogênio $\left(50,110,170,230\right.$ e $\left.290 \mathrm{~kg} \mathrm{ha}^{-1}\right)$ e colheita com quatro graus de umidade $(15,25,35$ e 45\%). Foi utilizada a linhagem de milho PGAG10051L. Realizaram-se testes de campo e laboratório. A linhagem estudada tolera baixa disponibilidade de nitrogênio, tendo alta eficiência no seu uso e responde positivamente ao aumento de nitrogênio quanto ao percentual de germinação, com melhores resultados acima de $170 \mathrm{~kg} \mathrm{~N} \mathrm{ha}^{-1}$. A linhagem tem alta capacidade de acúmulo de biomassa nas cariopses mesmo com baixo teor de umidade. Sementes colhidas com $25 \%$ de umidade apresentaram resultados satisfatórios de germinação e vigor. Recomenda-se aplicar a dose $170 \mathrm{~kg} \mathrm{ha}^{-1}$ de nitrogênio parcelada em quatro vezes para adubação em cobertura da linhagem de milho estudada. Palavras-chave: Adubação nitrogenada; Grau de umidade de sementes; Linhagens; Potencial fisiológico de sementes; Zea mays.
\end{abstract}

\footnotetext{
Abstract

An initial study on maize lines is essential to obtain hybrids. In the selection of strains, several parameters are observed to reach the crossing and commercialization. Some authors state that adequate nitrogen fertilization is needed to increase the corn economic productivity, considering $\mathrm{N}$ is the most required macronutrient by the crop. This nutrient performs
} 
diverse metabolic functions in seeds, contributing to their formation and nutritional reserve. Therefore, this paper aimed to evaluate the production and quality of irrigated corn lineage seeds under nitrogen doses and moisture levels at harvest time. The experiment was carried in the experimental area of the Goiano Federal Institute, Ceres Campus, Goiás State (GO), Brazil, and in its SAL. The experimental design was in randomized block, split plots, twenty treatments with five nitrogen rates $\left(50,110,170,230\right.$, and $\left.290 \mathrm{Kg} \mathrm{ha}^{-1}\right)$, and harvest took place with four moisture degrees $(15 \%, 25 \%, 35 \%$, and 45\%). A maize line the PGAG10051L. Field and laboratory tests were carried out. The studied strain tolerates low nitrogen availability and has high efficiency in its use. The strain responds positively to the nitrogen increase in relation to germination percentage with better results above $170 \mathrm{Kg}_{\text {of }} \mathrm{N} \mathrm{ha}^{-1}$. The strain has high capacity to accumulate biomass in caryopsis even with low moisture content. Seeds harvested with $25 \%$ moisture showed satisfactory results for germination and vigor. It is recommended to apply $170 \mathrm{Kg} \mathrm{de} \mathrm{N} \mathrm{ha}^{-1}$ nitrogen dose split in four times for topdressing the corn lineage studied in this paper.

Keywords: Nitrogen fertilization; Seed moisture degree; Seed physiological potential; Strains; Zea mays.

\section{Resumen}

Para obtener híbrido es fundamental um estúdio inicial realizado em líneas de máiz. Em la selección de cepas se observan vários parâmetros para llegar al cruce y comercialización. Para aumentar la productividad del máiz, algunos autores afirman que es necessária uma adecuada fertilización com nitrógeno, siendo el $\mathrm{N}$ el macronutriente más requerido por el cultivo. Realiza varias funciones metabólicas em las semillas, contribuyendo a su formación y reserva nutricional. Este trabajo tuvo como objetivo evaluar la producción y calidad de semillas de linaje de máiz irrigadas em función de las tasas de nitrógeno y los nivelesde humedad en la cosecha. El experimento se llevó a cabo en el área experimento se llevó a cabo em el área experimental del IF Goiano - Campus Ceres y en el LAS. El diseño experimental fue em bloques al azar, com cinco dosis de nitrógeno (50, 110, 179, 230 y $\left.290 \mathrm{Kg} \mathrm{ha}^{-1}\right)$ y cosecha com cuatro grados de humedad $(15,25,35$ y 45\%). Se utilizo la cepa de maíz PGAG10051L. Se realizaron pruebas de campo y de laboratório. La cepa estudiada tolera baja disponibilidad de nitrógeno, presenta alta eficiência en su uso y responde positivamente al aumento de nitrógeno em términos de porcentaje de germinación, com mejores resultados por encima de $170 \mathrm{Kg} \mathrm{N}$ $\mathrm{ha}^{-1}$. La cepa tiene uma alta capacidad para acumular biomasa en cariópside incluso con bajo contenido de humedad. Las semillas cosechadas con um $25 \%$ de humedad mostraron resultados satisfactorios en cuanto a germinación y vigor. Se recomenda aplicar la dosis de $170 \mathrm{Kg} \mathrm{N} \mathrm{ha}^{-1}$ de nitrógeno dividido en cuatro veces para el topdressing del linaje de maíz estudiado.

Palabras clave: Cepas; Contenido de humedad de la semilla; Fertilización nitrogenada; Potencial fisiológico de la semilla; Zea mays.

\section{Introdução}

O milho (Zea mays L.) está entre os principais cereais cultivados em todo o mundo, fornecendo produtos utilizados para a alimentação humana, animal e matérias-primas para a indústria, principalmente em função da quantidade e qualidade das reservas acumuladas nos grãos (Alves et al., 2015).

A produção de milho desempenha papel de suma importância no desenvolvimento socioeconômico de muitos países pela diversificação de suas utilizações, como produtos alimentares e importante fonte de etanol (Greaves \& Wang, 2017).

Na safra de 2018/2019, a produção foi de 98,5 milhões de toneladas (CONAB, 2019a). O estado de Goiás é o quarto maior produtor de milho do Brasil, participando com quase $10 \%$ de toda produção nacional, tendo a produção de milho na safra de 2018/2019 sido de 9,9 milhões de toneladas (CONAB, 2019b).

Segundo França Neto et al. (2010), o estabelecimento inicial de uma lavoura depende essencialmente do potencial fisiológico das sementes utilizadas. Sementes de alta qualidade resultam em plântulas fortes, bem vigorosas, desenvolvidas e que se estabelecem nas diferentes condições edafoclimáticas.

Qualquer programa de melhoramento só será bem-sucedido no desenvolvimento de novas cultivares se for eficiente na seleção dos genitores a serem utilizados nos cruzamentos, que resultem em híbridos com fenótipos de interesse agronômico (Rodrigues et al., 2009). Na seleção das linhagens, são observados parâmetros como produtividade, precocidade, resistência a pragas e doenças, adaptabilidade, nutrição, tolerância a fatores abióticos, como, por exemplo, déficit hídrico e altas temperaturas, consistindo em uma das etapas mais importantes e dispendiosas do programa de híbridos (Sawazaki et al., 2000). 
A obtenção de sementes de alta qualidade depende de diversos fatores, incluindo características da espécie, condições ambientais, época de colheita, método de secagem e práticas de armazenamento (Brooker et al., 1992). De acordo com Alves et al. (2001), há preocupação em se determinar a melhor época de colheita de sementes de milho, danificando-as o menos possível, evitando, assim, perdas. Normalmente, a colheita das sementes de milho pode ser feita com teores de água entre $27 \%$ e $35 \%$ (Ahrens et al., 1998), sendo necessário, portanto, fazer a secagem deste produto até o grau de umidade adequado para um armazenamento seguro que não comprometa a qualidade e o vigor fisiológico das sementes.

Nas sementes, as reservas de macro e micronutrientes são necessárias para o início do desenvolvimento das plântulas, sendo o nitrogênio (N) o nutriente mais requerido e mais capaz de limitar a produção da cultura do milho (Zucarell et al., 2012; Pereira et al., 2015). A qualidade fisiológica de sementes de linhagens de milho deve ser levada em consideração no melhoramento genético, devendo ser fornecidos ao programa híbridos com rápido estabelecimento inicial e germinação uniforme (Prazeres \& Coelho, 2016). De acordo com Souza et al. (2016), para aumentar a produtividade do milho, é necessário manejar a adubação nitrogenada de modo que a quantidade de $\mathrm{N}$ fornecida pelo solo seja capaz de reduzir gastos desnecessários com o fertilizante, buscando alta produtividade.

A eficiência no uso de $\mathrm{N}$ permite às plantas atingir altas produtividades com maior sustentabilidade (Ahlgren et al., 2008). Do Vale et al. (2012), avaliaram linhagens e híbridos de milho em estádio de V6 e concluíram que, independentemente da disponibilidade de $\mathrm{N}$, a eficiência na absorção de $\mathrm{N}$ foi mais importante para a eficiência no seu uso.

Para que um campo de sementes fique bem estabelecido, a disponibilidade de água é fator de suma importância, sendo caracterizada como uma prática agrícola que tem por objetivo suprir as necessidades hídricas das culturas no decorrer do seu ciclo (Sentelhas et al., 2001; Gomes, 2019).

Segundo Museck e Duser (1980) e Eck (1986), o milho necessita de água em todo o seu ciclo. A prática da irrigação é um fator crítico para a produção e pode ser justificada pela necessidade de melhorar os índices produtivos nas culturas (Cunha et al., 2013). Levando em consideração o estudo de linhagens de milho, saber se ela responde a épocas secas, se necessita de irrigação, quanto e quando irrigar é primordial para obter características ideais, como, por exemplo, um bom enchimento das sementes, havendo, porém, necessidade de mais estudos na área de irrigação em linhagens de milho.

Segundo Borges (2003), a produtividade da cultura do milho em condições irrigadas pode ser superior a 30 a $40 \%$ em relação à área do cultivo de sequeiro. O estudo de avaliação nutricional para a cultura do milho é mais específico em híbridos, entretanto há necessidade de maior entendimento sobre o comportamento das linhagens dessa cultura para melhores respostas ao manejo nutricional. Diante disto, este trabalho teve como objetivo avaliar a produção e a qualidade de sementes de linhagem de milho irrigado em função de doses de nitrogênio e graus de umidade na colheita.

\section{Metodologia}

O trabalho foi conduzido em campo, na área experimental do IF Goiano - Campus Ceres e no Laboratório de Análise de Sementes (LAS), em Ceres, GO. Os dados de umidade relativa do ar, temperatura e pluviosidade foram coletados diariamente no período experimental na estação meteorológica do Instituto Federal Goiano - Campus Ceres.

A umidade relativa do ar máxima variou de $79 \%$ a $59 \%$ e a mínima de $11 \%$ a $38 \%$. Para o bom desenvolvimento da cultura, é indicado que na época de floração a umidade relativa do ar esteja acima de 66\% (Galvão, 2015). A umidade para o período foi a ideal para a cultura do milho.

A temperatura máxima na época da realização do experimento foi de $42^{\circ} \mathrm{C}$, enquanto a mínima foi de $16,2^{\circ} \mathrm{C}$. A temperatura ideal para o desenvolvimento da cultura do milho, da emergência à floração, está compreendida entre $24^{\circ} \mathrm{Ce} 30^{\circ} \mathrm{C}$ (Cruz et al., 2010). Então, a temperatura para o período da realização do presente trabalho foi ideal para a cultura do milho. 
O solo da área experimental foi classificado como Latossolo Vermelho, de relevo plano. Foi feita a análise das características químicas e físicas do solo da área experimental, Tabela 1, no Laboratório de Solos do IF Goiano - Campus CeresGO. A metodologia de coleta das amostras do solo em campo foi feita de acordo com a descrita por Arruda et al. (2014).

Tabela 1. Análise química e física do solo da área experimental. Ceres - GO, 2019.

\begin{tabular}{|c|c|c|c|c|c|c|c|c|c|c|c|c|c|c|}
\hline \multirow{2}{*}{ Areia } & Silte & Argila & pH & M.O & $\mathbf{C a}$ & Mg & Al & $\mathbf{H}+\mathbf{A l}$ & K & $\mathbf{T}$ & K & $\mathbf{P}$ & V & $\mathbf{m}$ \\
\hline & \multicolumn{2}{|c|}{ 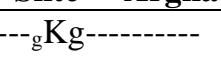 } & \multirow[t]{2}{*}{$\mathrm{em} \mathrm{H}_{2} \mathrm{O}$} & \multirow[t]{2}{*}{$\mathrm{g}_{\mathrm{dm}}^{3}$} & \multicolumn{6}{|c|}{ 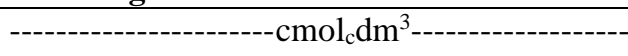 } & \multicolumn{2}{|c|}{$----\mathrm{m}_{\mathrm{g}} \mathrm{dm}^{3}----$} & \multicolumn{2}{|c|}{------\%----- } \\
\hline & & & & & & & & & & & & & & \\
\hline 336 & 77 & 586 & 6.2 & 17.4 & 3.0 & 1.6 & 0.0 & 1.3 & 0.4 & 6.3 & 166.7 & 15.8 & 79.5 & 0.0 \\
\hline
\end{tabular}

Fonte: Autores.

O delineamento experimental em campo para avaliação da qualidade de sementes em função das doses e graus de umidade na colheita foi em blocos casualizados (DBC), em arranjo fatorial 5x4, em parcelas subdivididas, com 20 tratamentos, sendo cinco doses de nitrogênio $\left(50,110,170,230\right.$ e $\left.290 \mathrm{~kg} \mathrm{ha}^{-1}\right)$ e colheita com quatro graus de umidade $(15,25,35$ e $45 \%$ de umidade). Foram feitas quatro repetições para cada tratamento. A pesquisa deste presente trabalho é de campo e laboratório, seguindo a metodologia científica de Estrela (2018).

Para avaliar o crescimento da planta, foi utilizado o teste de médias (Tukey), com arranjo fatorial $5 \times 3$, com 15 tratamentos, sendo cinco doses de nitrogênio $\left(50,110,170,230\right.$ e $\left.290 \mathrm{Kg} \mathrm{ha}^{-1}\right)$ e três períodos diferentes de avaliação (estágios V10, V14 e R1). Para as variáveis altura de inserção de inserção da primeira espiga e avaliação das espigas, foi utilizado teste de médias com caracterização de experimento simples.

As sementes utilizadas no experimento foram doadas pela empresa Limagrain S/A, tendo sido utilizada a linhagem PGAG10051L, considerada uma linhagem genética fêmea de milho, de ciclo tardio, tendo atributos de boa produtividade, com tipo de grão semidentado, coloração amarelo alaranjada, tendo a tecnologia VIP3.

A adubação de base foi feita de acordo com a análise de solo e com os parâmetros das Recomendações para o Uso de Corretivos e Fertilizantes em Goiás - 5 a Aproximação (1988). Foi utilizada a fórmula 4-30-10 nas doses de $20 \mathrm{~kg} \mathrm{ha}^{-1}$ de N, 150 $\mathrm{kg} \mathrm{ha}^{-1}$ de $\mathrm{P}_{2} \mathrm{O}_{5}$ e $50 \mathrm{~kg} \mathrm{ha}^{-1}$ de $\mathrm{K}_{2} \mathrm{O}$ para o plantio. A adubação com $\mathrm{P}_{2} \mathrm{O}_{5}$ foi feita na semeadura. Para a adubação de cobertura, foram aplicados $90 \mathrm{~kg} \mathrm{ha}^{-1} \mathrm{de}_{2} \mathrm{O}$, parcelados em quatro vezes, nas fases V2, V4, V6 e V8. As cinco doses de N (50, 110, 170, 230 e $290 \mathrm{~kg} \mathrm{ha}^{-1}$ ) foram aplicadas em cobertura e parcelada nos estádios V2, V4, V6 e V8, e a fonte utilizada foi a ureia. Todas as adubações foram feitas manualmente, com clima fresco, sem sol, com o solo úmido e incorporadas ao solo.

O monitoramento das umidades das sementes começou no estádio R5. A umidade das sementes passou a ser monitorada diariamente. Colheram-se quatro espigas em pontos distintos das parcelas de cada tratamento, as quais foram despalhadas e debulhadas manualmente no LAS. A metodologia utilizada para a determinação da umidade foi de acordo com Brasil (2009). Foram feitas quatro colheitas de espigas de milho com quatro graus de umidade diferentes (15, 25, 35 e $45 \%$ b.u $)$. As sementes foram submetidas aos testes laboratoriais com umidade alta e com umidade baixa. Foi feita a secagem natural, em temperatura ambiente a $25^{\circ} \mathrm{C}$ até chegar à umidade de $13 \%$. A debulha foi feita manualmente.

As variáveis analisadas em campo foram altura de plantas, altura de inserção da primeira espiga, diâmetro do colmo, comprimento das espigas, diâmetro das espigas, número de sementes por fileira, número de fileira, número sementes por espiga e produtividade.

As variáveis analisadas em laboratório foram grau de umidade, teste padrão de germinação, peso de mil sementes, condutividade elétrica, teste de tetrazólio, teste de envelhecimento acelerado, sementes infestadas e teor de nitrogênio nas sementes. Foram escolhidas cinco espigas ao acaso de cada parcela de cada tratamento para os testes laboratoriais, tendo a 
umidade das sementes sido corrigida para 13\%. Os testes laboratoriais seguiu-se a metodologia de Brasil (2009). Para o teste de teor de nitrogênio nas sementes, seguiu-se a metodologia de Kjeldhal (1883).

A avaliação da emergência de plântulas de milho foi feita em canteiros, utilizando o substrato areia com quatro repetições de 50 sementes de cada tratamento. As plântulas foram contadas como normais aos sete dias após a semeadura (Bono et al., 2008).

Os dados foram submetidos à análise de variância pelo teste $\mathrm{F}$ a $5 \%$ de probabilidade e quando houve significância foi aplicada a análise de regressão utilizando o programa estatístico SISVAR versão 2011. Os gráficos foram elaborados no SigmaPlot v. 12.5, SYSTAT SOFTWARE versão 2013.

\section{Resultados}

A Tabela 2 mostra os resultados da análise de variância para as variáveis altura de plantas (AP) e diâmetro do colmo das plantas (DC). Como pode ser observado, houve significância a 5\% de probabilidade para os estádios e doses de N, ou seja, as doses de $\mathrm{N}$ influenciaram na altura de plantas.

Tabela 2. Análise de variância para altura de plantas de milho e diâmetro do colmo de plantas de milho (DC) em relação aos estágios da linhagem de milho (V10, V14 e R1) e às doses de N (50, 110, 170, 230 e 290 kg de N ha-1 . Ceres, GO. 2019.

\begin{tabular}{cccc}
\hline FV & GL & AP & DC \\
\hline Bloco & 3 & $0,0^{\text {ns }}$ & $0,0^{* *}$ \\
Estádio & 2 & $3,46^{* *}$ & $0,50^{* *}$ \\
Resíduo 1 & 6 & 0,0 & 0,0 \\
Doses de N & 4 & $0,20^{* *}$ & $0,0^{\text {ns }}$ \\
Int Dose N x Estádio & 8 & $0,01^{* *}$ & $0,0^{\text {ns }}$ \\
Resíduo 2 & 36 & 0,0 & 0,0 \\
\hline CV \% & & 2,01 & 1,64 \\
CV \% & & 2,87 & 1,81 \\
\hline
\end{tabular}

QM: quadrado médio; GL: grau de liberdade; CV: coeficiente de variação; ${ }^{\text {ns }}$ não significativo no teste $\mathrm{F}$ ao nível de $5 \%$ de probabilidade; $* *$ significativo no teste $\mathrm{F}$ ao nível de $5 \%$ de probabilidade.

Fonte: Autores.

Observa-se na Figura 1 resposta positiva aos tratamentos, visto que, com aumento das doses de N, houve também aumento na altura das plantas de milho. $\mathrm{O}$ tratamento $4\left(230 \mathrm{~kg} \mathrm{de} \mathrm{N}_{\text {ha }}{ }^{-1}\right)$ mostrou maior altura de plantas nos estágios $\mathrm{V} 14 \mathrm{e}$ R1. A dose máxima de $\mathrm{N}$ do tratamento $5\left(290 \mathrm{~kg}\right.$ de $\left.\mathrm{N} \mathrm{ha}^{-1}\right)$ mostrou resultado de altura inferior ao tratamento 4 (230 kg de $\mathrm{N}$ ha $^{-1}$ ) nos estágios V14 e R1. Os resultados do diâmetro do colmo mostraram maior diâmetro no estádio R1 das plantas da linhagem de milho. 
Figura 1. Altura de plantas de milho nos estágios V10, V14 e R1 em relação às doses de N (50, 110, 170, 230 e 290 kg de N $\left.\mathrm{ha}^{1}\right)$. Ceres GO, 2019.

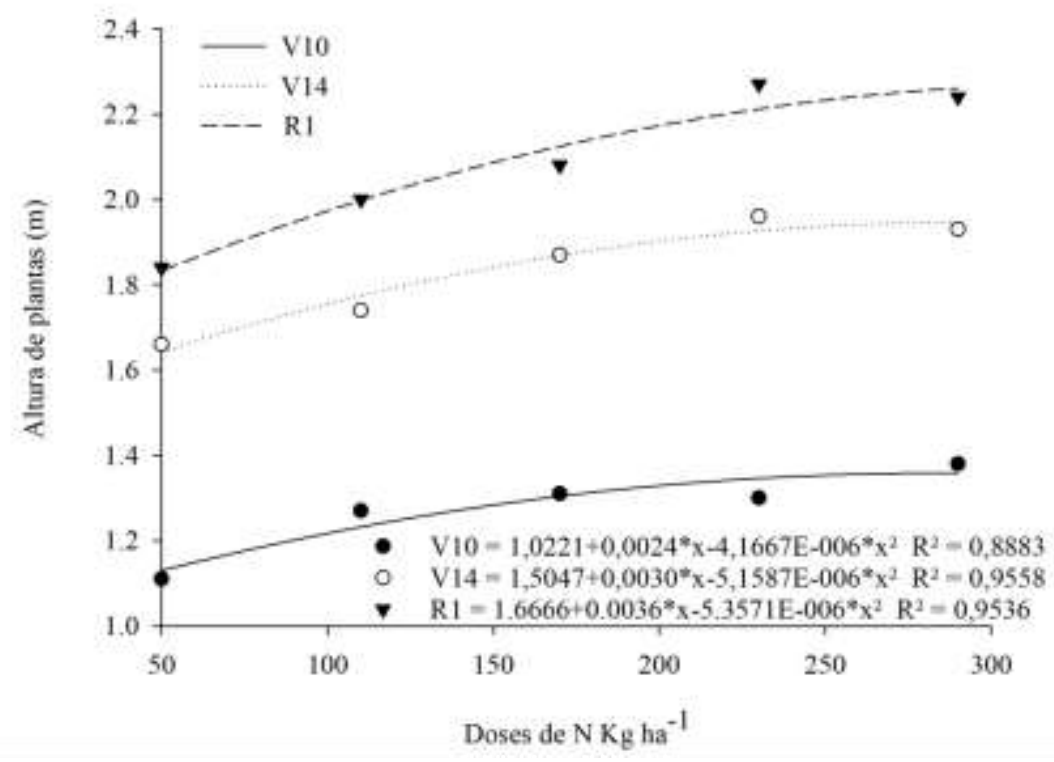

Fonte: Autores.

A Tabela 3 mostra os resultados da análise de variância das variáveis comprimento das espigas de milho (CESP) e diâmetro das espigas de milho (DESP). Como pode ser observado, houve interação das variáveis tanto para graus de umidade da colheita quanto para doses de $\mathrm{N}$. A dose de $50 \mathrm{~kg}$ de $\mathrm{N} \mathrm{ha}^{-1}$ apresentou maior comprimento em comparação com as outras doses estudadas neste trabalho, a dose de $290 \mathrm{~kg}_{\text {de }} \mathrm{N} \mathrm{ha}^{-1}$ apresentou comprimento menor. Na variável diâmetro das espigas, quando foram colhidas com $45 \%$ de umidade, elas apresentaram diâmetro maior, provavelmente em razão de as espigas deverem ter maior quantidade de água presentes, pois, conforme foram diminuindo os graus de umidade, o diâmetro foi diminuindo.

Tabela 3. Análise de variância para o comprimento das espigas (CESP) e diâmetro do colmo da espiga (DESP), em relação aos graus de umidade da colheita (GUC) $(45 \%, 35 \%, 25 \%$ e $15 \%$ de umidade) e às doses de N (50, 110, 170, 230 e $290 \mathrm{~kg}$ de $\mathrm{N}$ ha 1. Ceres, GO. 2019.

\begin{tabular}{cccc}
\hline FV & GL & CESP & DESP \\
\hline Bloco & 3 & $0,07^{\text {ns }}$ & $0,68^{\text {ns }}$ \\
GUC & 3 & $0,77^{* *}$ & $5,22^{* *}$ \\
Resíduo 1 & 9 & 0,12 & 0,19 \\
Doses de N & 4 & $6,06^{* *}$ & $55,15^{* *}$ \\
Int DN x C & 12 & $0,39^{\text {ns }}$ & $1,91^{* *}$ \\
Resíduo 2 & 48 & 0,28 & 0,32 \\
CV \% & & 1,85 & 1,16 \\
CV \% & & 2,82 & 1,5 \\
\hline
\end{tabular}

QM: quadrado médio; GL: grau de liberdade; CV: coeficiente de variação; ${ }^{\text {ns }}$ não significativo no teste $\mathrm{F}$ ao nível de $5 \%$ de probabilidade; ** significativo no teste $\mathrm{F}$ ao nível de $5 \%$ de probabilidade.

Fonte: Autores.

A Tabela 4 mostra os resultados das análises de variância para as variáveis altura de inserção da primeira espiga, número de sementes por fileira, número de fileira e número de sementes por espiga. Como pode ser observado na Tabela 4, NSF, NSE e 
NF não obtiveram significância para as doses de $\mathrm{N}$ estudadas neste trabalho, ou seja, as doses de $\mathrm{N}$ não interferiram no número de sementes por fileira, espiga e no número de fileiras. Apenas para altura de inserção da primeira espiga, houve interação significativa em relação às doses de $\mathrm{N}$.

Tabela 4. Análise de variância para altura de inserção da primeira espiga (AIPE), número de sementes por fileira (NSF), número de fileira (NF), número de sementes por espiga (NSE), em função das doses de N (50, 110, 170, 230 e 290 kg de N ha-1). Ceres, GO. 2019.

\begin{tabular}{cccccc}
\hline FV & GL & AIPE & NSF & NF & NSE \\
\hline Bloco & 3 & $0,0^{\text {ns }}$ & $0,98^{\text {ns }}$ & $0,17^{\text {ns }}$ & $151,65^{\text {ns }}$ \\
Doses de N & 4 & $0,0^{* *}$ & $0,25^{\text {ns }}$ & $0,13^{\text {ns }}$ & $58,55^{\text {ns }}$ \\
Resíduo & 12 & 0,00 & 1,31 & 0,17 & 292,15 \\
CV\% & & 0,59 & 3,86 & 3,74 & 4,82 \\
\hline
\end{tabular}

QM: quadrado médio; GL: grau de liberdade; CV: coeficiente de variação; ns não significativo no teste F ao nível de $5 \%$ de probabilidade; ** significativo no teste $\mathrm{F}$ ao nível de $5 \%$ de probabilidade.

Fonte: Autores.

A Figura 2 mostra que o tratamento $4\left(230 \mathrm{~kg}\right.$ de $\left.\mathrm{N} \mathrm{ha}^{-1}\right)$ proporcionou maior altura de inserção da primeira espiga, com média de $1,35 \mathrm{~m}$.

Figura 2. Altura de inserção da primeira espiga de milho em relação às doses de N (50,110, 170, 230 e 290 kg de N ha- $\left.{ }^{1}\right)$. Ceres GO, 2019.

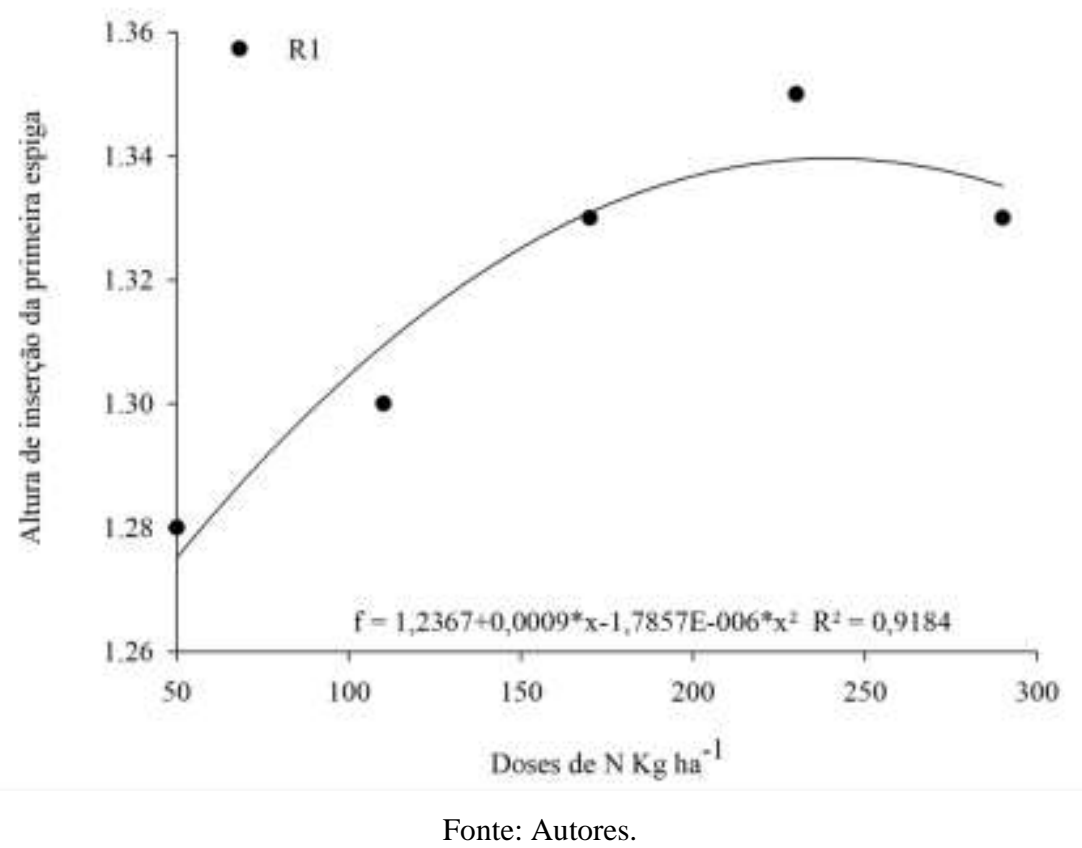

A Figura 3 mostra o resultado do TPG em relação às doses de N e aos graus de umidade das colheitas. As sementes em todas as doses de $\mathrm{N}$ estudadas apresentaram melhores resultados de germinação quando colhidas com grau de umidade de $25 \%$. 
Figura 3. Resultado de TPG em relação aos quatro graus de umidade das colheitas $(45,35,25,15 \%$ de b.u) e às doses de $\mathrm{N}(50$, 110, 170, 230 e $290 \mathrm{~kg} \mathrm{ha}^{-1}$ ), sementes sem o processo da secagem. Ceres GO, 2019.

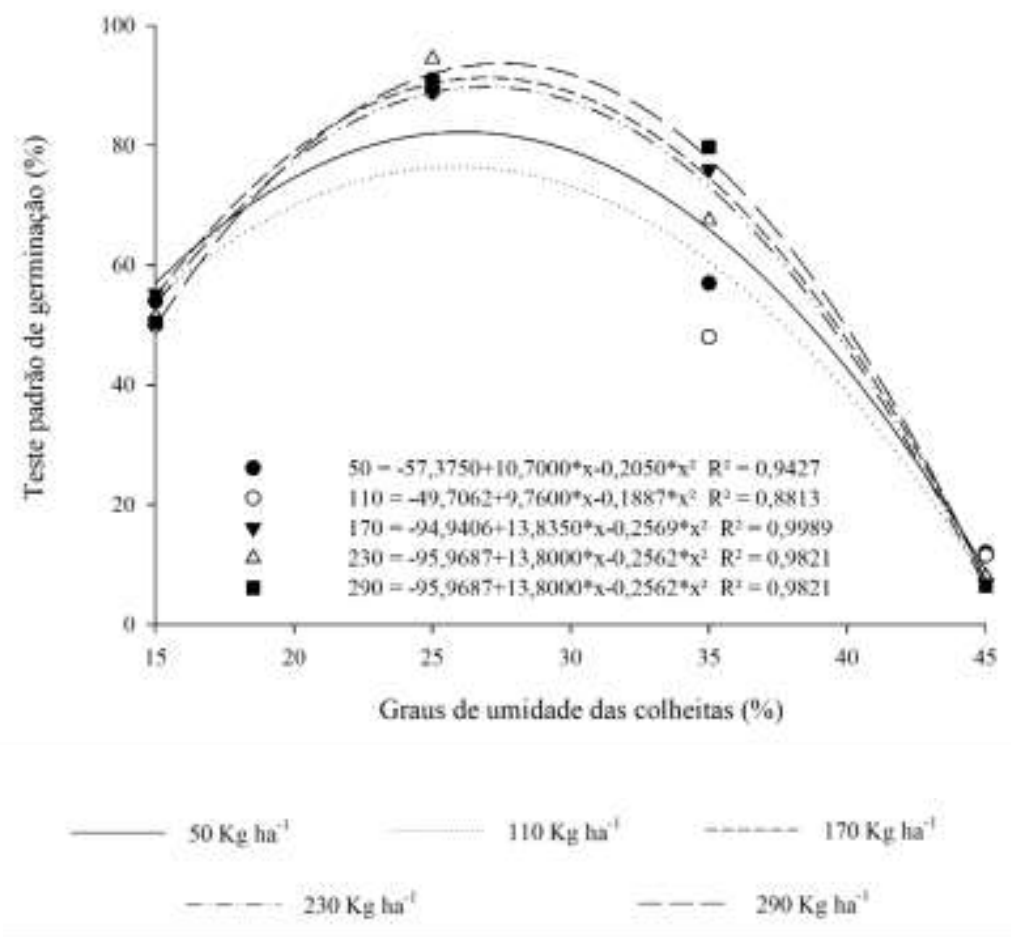

Fonte: Autores.

A Tabela 5 mostra a análise de variância das variáveis grau de umidade (GU), teste padrão de germinação (TPG), peso de mil sementes (PMS), condutividade elétrica (CE), tetrazólio (TZ), envelhecimento acelerado (EA), sementes infestadas (SI), canteiro em areia (CA) e produtividade (PROD), parâmetros avaliados com as sementes sem o processo de secagem e com o processo de secagem (sementes a $13 \%$ de umidade). A produtividade das sementes foi calculada somente quando atingiram $13 \%$ de umidade. 
Tabela 5. Análise de variância para grau de umidade (GU), teste padrão de germinação (TPG), peso de mil sementes (PMS), condutividade elétrica (CE), tetrazólio (TZ), envelhecimento acelerado (EA), sementes infestadas (SI), canteiro de areia (CA), sementes sem secagem e com secagem (13\% de umidade). Ceres, GO, 2019.

\begin{tabular}{|c|c|c|c|c|c|c|c|c|c|c|}
\hline \multicolumn{11}{|c|}{ ANÁLISE DE VARIÂNCIA PARA AS VARIÁVEIS SEM O PROCESSO DE SECAGEM } \\
\hline FV & GL & GU & TPG & PMS & $\mathbf{C E}$ & $\mathbf{T Z}$ & EA & SI & CA & \\
\hline Bloco & 3 & $0,02 \mathrm{~ns}$ & $33,83 \mathrm{~ns}$ & $591,61 \mathrm{~ns}$ & $13,40 \mathrm{~ns}$ & $2,07 \mathrm{~ns}$ & $45,53 \mathrm{~ns}$ & $1,68 \mathrm{~ns}$ & $45,54 \mathrm{~ns}$ & \\
\hline GUC & 3 & $3286,21 * *$ & $23354,76^{* *} *$ & $49094,59 * *$ & $10624,58^{* *}$ & $13866,61 * *$ & $22332,23 * *$ & $490,05^{* *}$ & $24598,64 * *$ & \\
\hline Resíduo 1 & 9 & 0,11 & 38,4 & 287,53 & 6,4 & 2,75 & 20,58 & 1,68 & 28,95 & \\
\hline $\begin{array}{c}\text { Doses de } \\
\mathbf{N} \\
\text { Int. DN x }\end{array}$ & 4 & $0,05 \mathrm{~ns}$ & $145,91 * *$ & $202,40 \mathrm{~ns}$ & $65,60 * *$ & $19,51 * *$ & $99,01 * *$ & $0,26 \mathrm{~ns}$ & $203,31 * *$ & \\
\hline GUC & 12 & $0,15 \mathrm{~ns}$ & $209,19 * *$ & $228,06 \mathrm{~ns}$ & $84,19 * *$ & $15,14 * *$ & $149,67 * *$ & $0,26 \mathrm{~ns}$ & $166,64 * *$ & \\
\hline Resíduo 2 & 48 & 0,17 & 20,42 & 223,70 & 4,28 & 2,87 & 19,81 & 0,23 & 25,64 & \\
\hline CV\% & & 1,13 & 11,38 & 5,04 & 6,1 & 2,16 & 8,72 & 52,42 & 9,33 & \\
\hline $\mathrm{CV} \%$ & & 1,4 & 8,3 & 4,45 & 4,99 & 2,2 & 8,55 & 19,6 & 8,78 & \\
\hline \multicolumn{11}{|c|}{ ANÁLISE DE VARIÂNCIA PARA AS VARIÁVEIS COM O PROCESSO DE SECAGEM (13\% umidade) } \\
\hline FV & GL & GU & TPG & PMS & $\mathbf{C E}$ & $\mathbf{T Z}$ & EA & SI & CA & PROD \\
\hline Bloco & 3 & $0,81^{\mathrm{ns}}$ & $1,68^{\mathrm{ns}}$ & $63,79^{\text {ns }}$ & $3,60 * *$ & $2,40^{\mathrm{ns}}$ & $1,83^{\mathrm{ns}}$ & $0,10^{\mathrm{ns}}$ & $1,93^{\mathrm{ns}}$ & $1184981,67 * *$ \\
\hline GUC & 3 & $0,03^{\mathrm{ns}}$ & $10898,98 * *$ & 247,51 & $3085,42 * *$ & $14470,50 * *$ & $12297,30 * *$ & $696,20 * *$ & $11142,30 * *$ & $40114369,11^{* *}$ \\
\hline $\begin{array}{c}\text { Resíduo } 1 \\
\text { Doses de }\end{array}$ & 9 & 0,19 & 7,72 & 42,66 & 0,69 & 1,67 & 2,2 & 0,1 & 1,34 & 127346 \\
\hline $\begin{array}{c}\text { N } \\
\text { Int. DN x }\end{array}$ & 4 & $0,35^{\mathrm{ns}}$ & $27,71 * *$ & $19,03^{\mathrm{ns}}$ & $3,40^{\mathrm{ns}}$ & $14,05 * *$ & $65,42 * *$ & $1,04^{\mathrm{ns}}$ & $19,17 * *$ & $411572,41^{\mathrm{ns}}$ \\
\hline GUC & 12 & $0,16^{\mathrm{ns}}$ & $19,16^{* *}$ & $61,55^{\mathrm{ns}}$ & $4,78 * *$ & $13,37 * *$ & $37,42 * *$ & $1,04 * *$ & $14,43 * *$ & $320347,22^{\mathrm{ns}}$ \\
\hline Resíduo 2 & 48 & 0,17 & 4,71 & 33,39 & 1,86 & 2,49 & 1,85 & 0,48 & 2,41 & 182810,48 \\
\hline CV\% & & 3,27 & 3,7 & 2,39 & 1,04 & 1,69 & 1,98 & 10,72 & 1,52 & 7,74 \\
\hline CV\% & & 3,14 & 2,89 & 2,12 & 1,7 & 2,05 & 1,82 & 23,69 & 1,96 & 9,28 \\
\hline
\end{tabular}

QM: quadrado médio; GL: grau de liberdade; CV: coeficiente de variação; ${ }^{\text {ns }}$ não significativo no teste $\mathrm{F}$ ao nível de $5 \%$ de probabilidade; ** significativo no teste $\mathrm{F}$ ao nível de $5 \%$ de probabilidade.

Fonte: Autores.

Analisando as variáveis que não passaram pelo processo de secagem, pode-se observar que as variáveis GU, PMS e SI apresentaram significância para o fator grau de umidade de colheita, já para o TPG, CE, TZ, EA e CA, houve interação entre as doses de $\mathrm{N}$ e colheita.

A Figura 4 mostra o resultado do peso de mil sementes em relação aos quatro graus de umidade. As sementes, quando colhidas com maior grau de umidade (45\%), apresentaram maior peso para mil sementes, quanto colhidas com menor grau de umidade das sementes (15\%), apresentaram menor peso para mil sementes. 
Research, Society and Development, v. 10, n. 9, e23410917144, 2021

(CC BY 4.0) | ISSN 2525-3409 | DOI: http://dx.doi.org/10.33448/rsd-v10i9.17144

Figura 4. Peso de mil sementes em relação aos quatro graus de umidade, sementes sem o processo da secagem. Ceres GO, 2019.

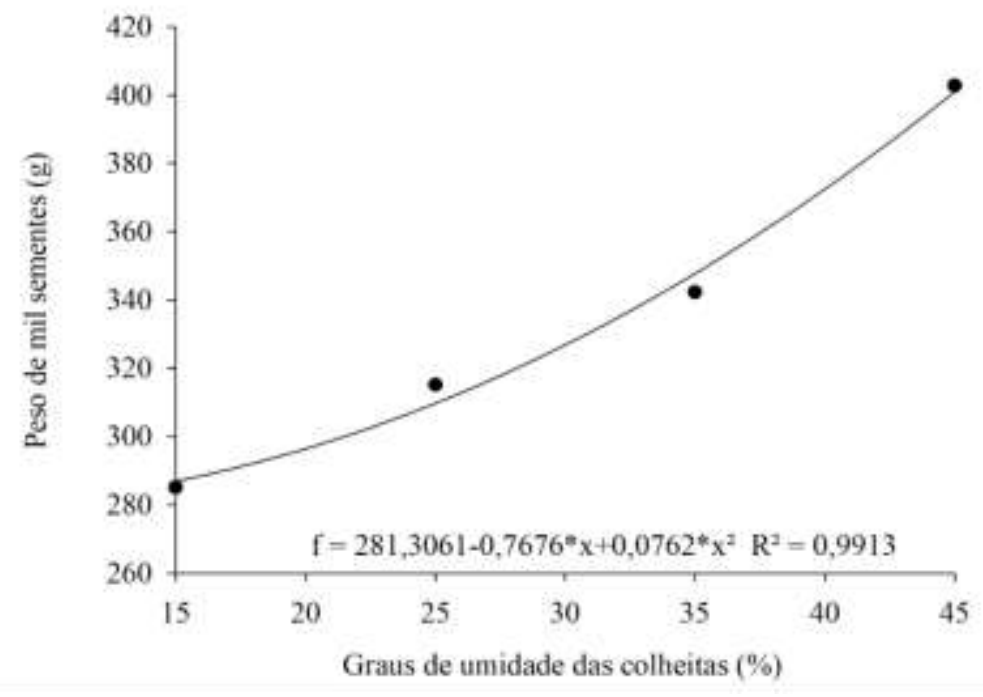

Fonte: Autores.

A Figura 5 mostra o resultado da condutividade elétrica em relação às doses de $\mathrm{N}$ e os graus de umidade das colheitas. Quando as sementes foram colhidas com grau de umidade em 15\%, aquelas com as doses de N estudadas apresentaram maiores resultados para condutividade elétrica.

Figura 5. Condutividade elétrica em relação aos quatro graus de umidade das colheitas e às doses de N, sementes sem o processo da secagem. Ceres GO, 2019.

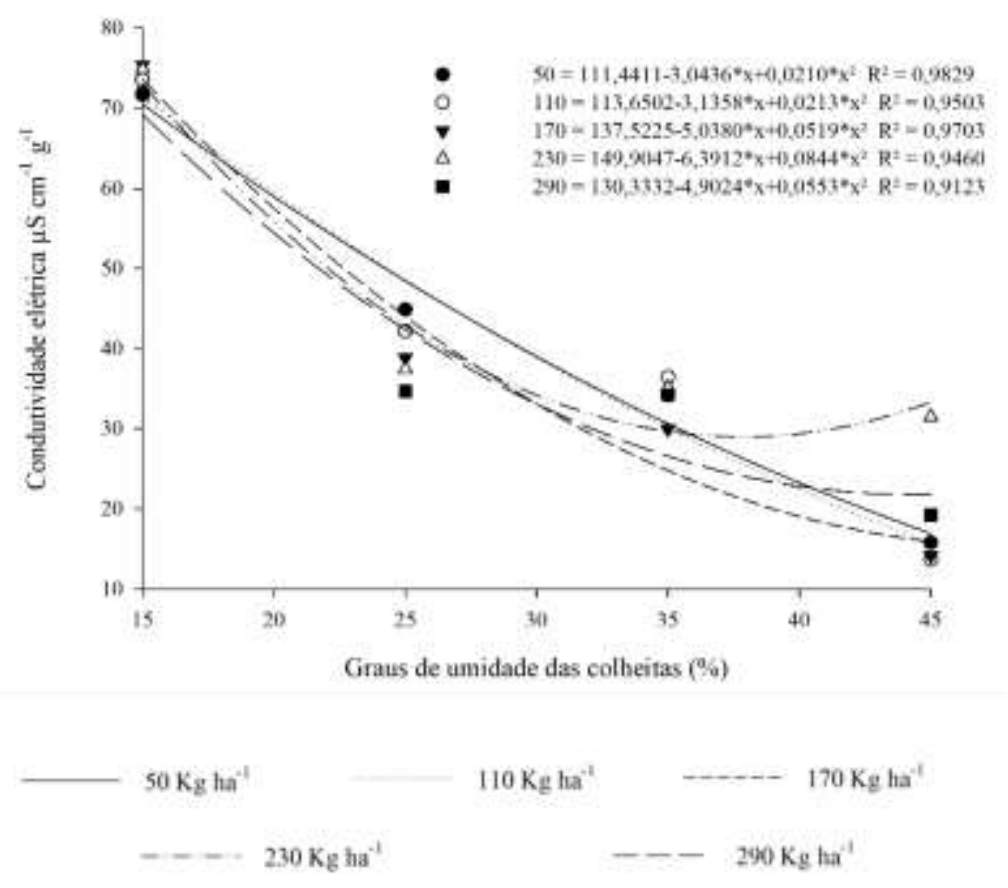

Fonte: Autores. 
Research, Society and Development, v. 10, n. 9, e23410917144, 2021

(CC BY 4.0) | ISSN 2525-3409 | DOI: http://dx.doi.org/10.33448/rsd-v10i9.17144

A Figura 6 mostra o resultado do teste de tetrazólio em relação às doses de $\mathrm{N}$ e aos graus de umidade. As sementes da linhagem de milho apresentaram melhores resultados quando foram colhidas com grau de umidade de $25 \%$.

Figura 6. Teste de tetrazólio em relação aos quatro graus de umidade das colheitas e às cinco doses de $\mathrm{N}$, sementes sem o processo da secagem. Ceres GO, 2019.

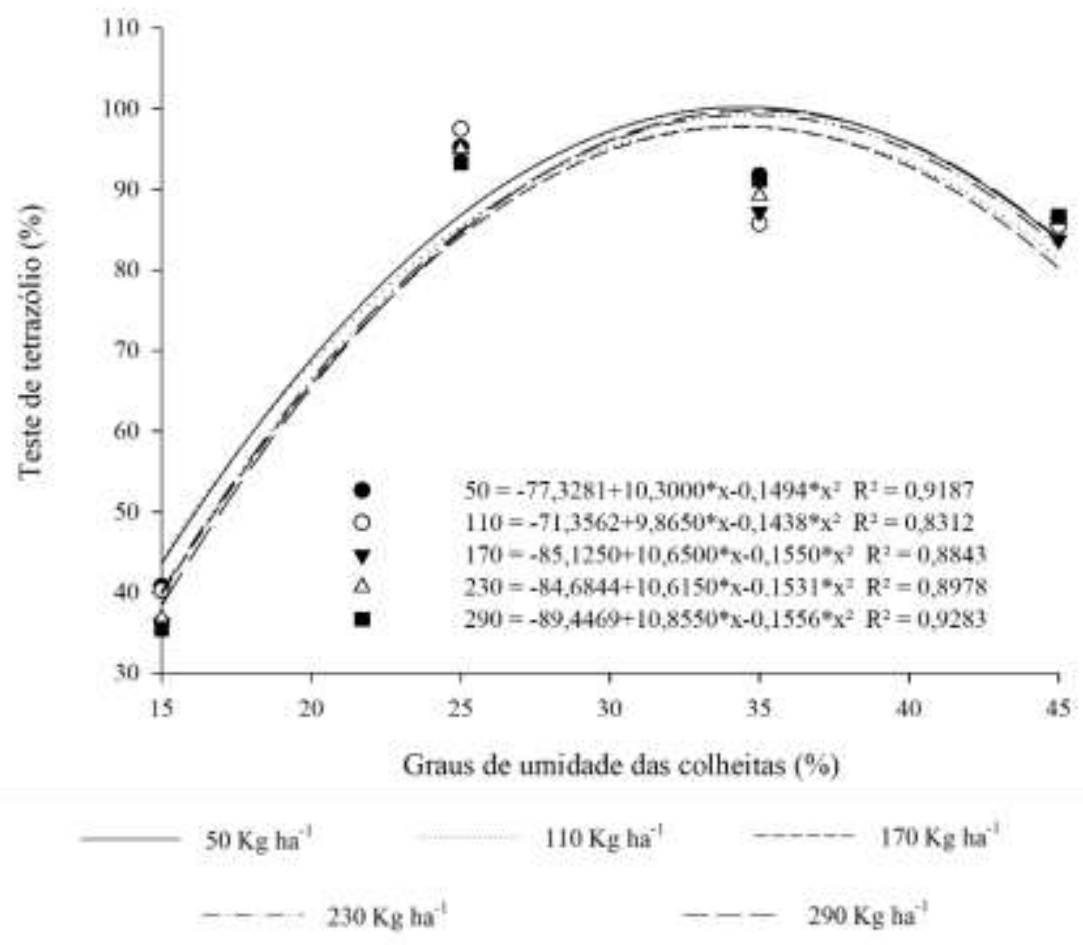

Fonte: Autores.

A Figura 7 mostra o resultado do envelhecimento acelerado em relação às doses de $\mathrm{N}$ e aos graus de umidade das colheitas. As sementes da linhagem de milho com as doses de $\mathrm{N}$ estudadas, quando submetidas ao teste de envelhecimento acelerado com as sementes colhidas com $45 \%$ de grau de umidade, apresentaram resultados inferiores em comparação com as sementes que tiveram colheita apresentando $25 \%$. 
Figura 7. Teste de envelhecimento acelerado em relação aos quatro graus de umidade das colheitas e às cinco doses de $\mathrm{N}$, sementes sem o processo da secagem. Ceres GO, 2019.

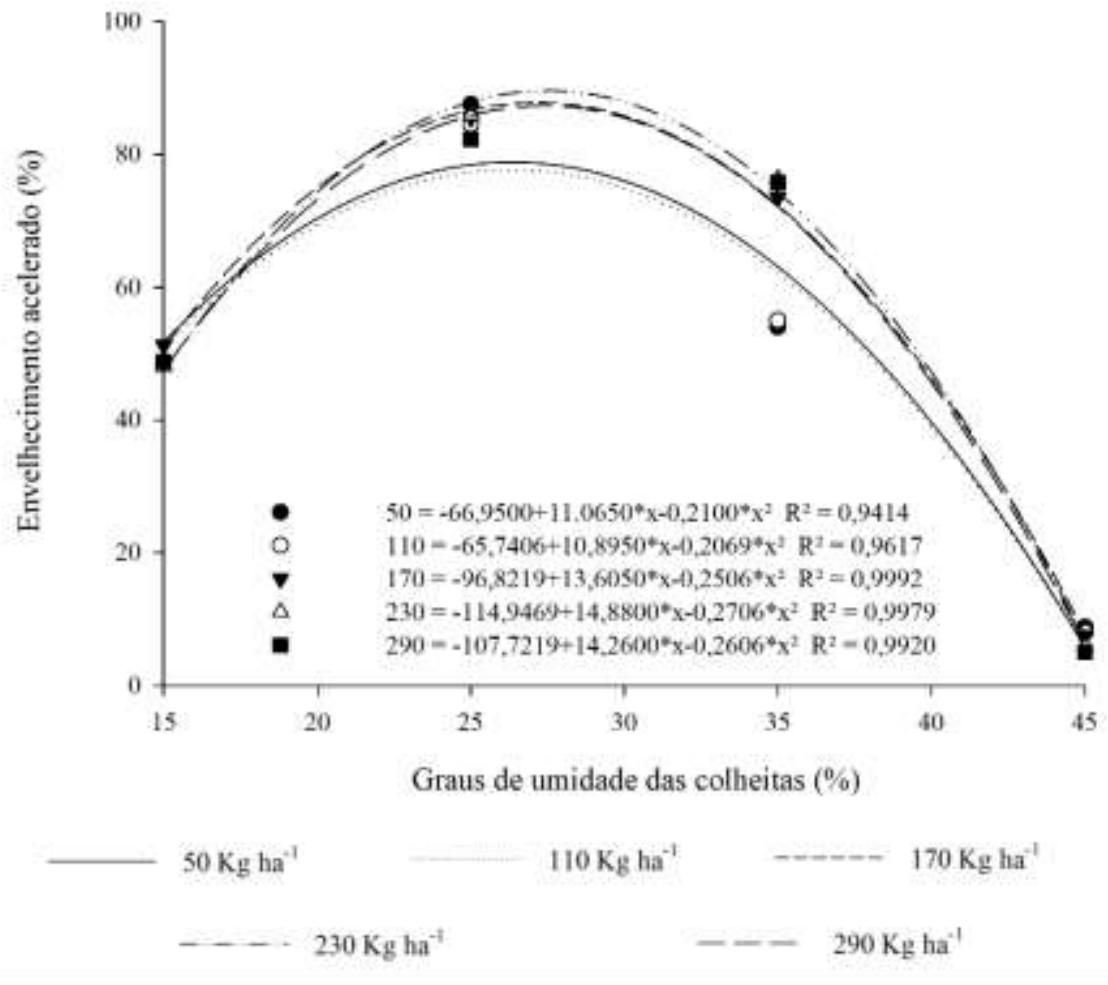

Fonte: Autores.

A linhagem de milho estudada neste trabalho apresentou infestação das sementes somente quando colhidas com $15 \%$ de umidade, apresentando em torno de $10 \%$ de infestação, resultado considerado extremamente alto para infestação das sementes de milho, o que provavelmente explica que as sementes foram fazendo seu processo de secagem ao pé da planta, tendo se tornado susceptíveis ao ataque de patógenos. Quando as sementes foram colhidas com maiores graus de umidade, elas não apresentaram resultado de infestação.

A Figura 8 mostra o resultado do canteiro com substrato areia em relação às doses de $\mathrm{N}$ e aos graus de umidade. Podese observar que, quando as sementes foram colhidas com $45 \%$ de umidade e foram submetidas ao teste de canteiro, a emergência foi muito baixa em comparação com as sementes com $25 \%$. 
Figura 8. Canteiro de areia em relação aos quatro graus de umidade das colheitas e às cinco doses de N, sementes sem o processo da secagem. Ceres GO, 2019.

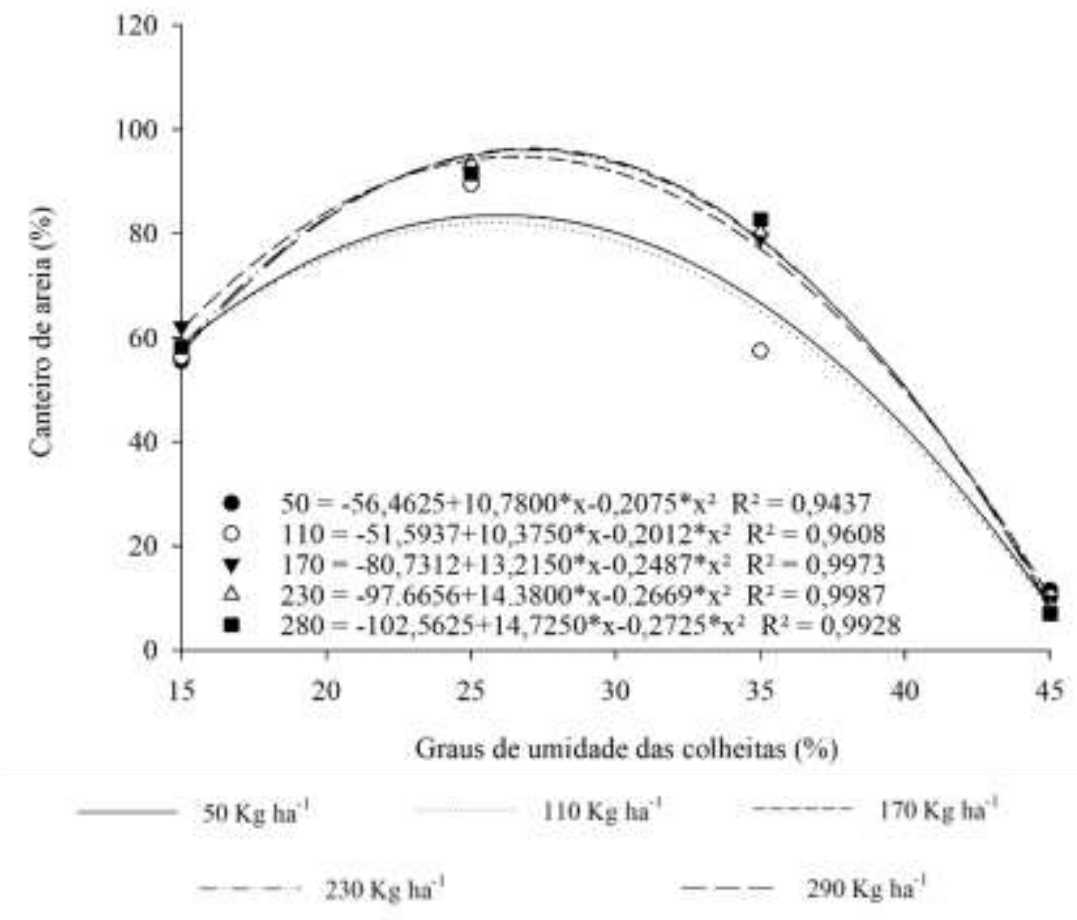

Fonte: Autores.

Analisando as variáveis que passaram pelo processo de secagem, na Figura 9 tem-se o TPG em relação às doses de $\mathrm{N}$ e aos graus de umidade das colheitas com as sementes já submetidas à secagem. Pode-se observar que as sementes colhidas aos $25 \%$ de umidade, quando submetidas aos $13 \%$ de umidade, apresentaram melhores resultados de germinação para todas as doses de $\mathrm{N}$ estudadas. 
Figura 9. TPG das sementes de milho com umidade corrigida a $13 \%$ em relação às doses de $\mathrm{N}$ e aos graus de umidade das colheitas, sementes submetidas ao processo da secagem. Ceres GO, 2019.

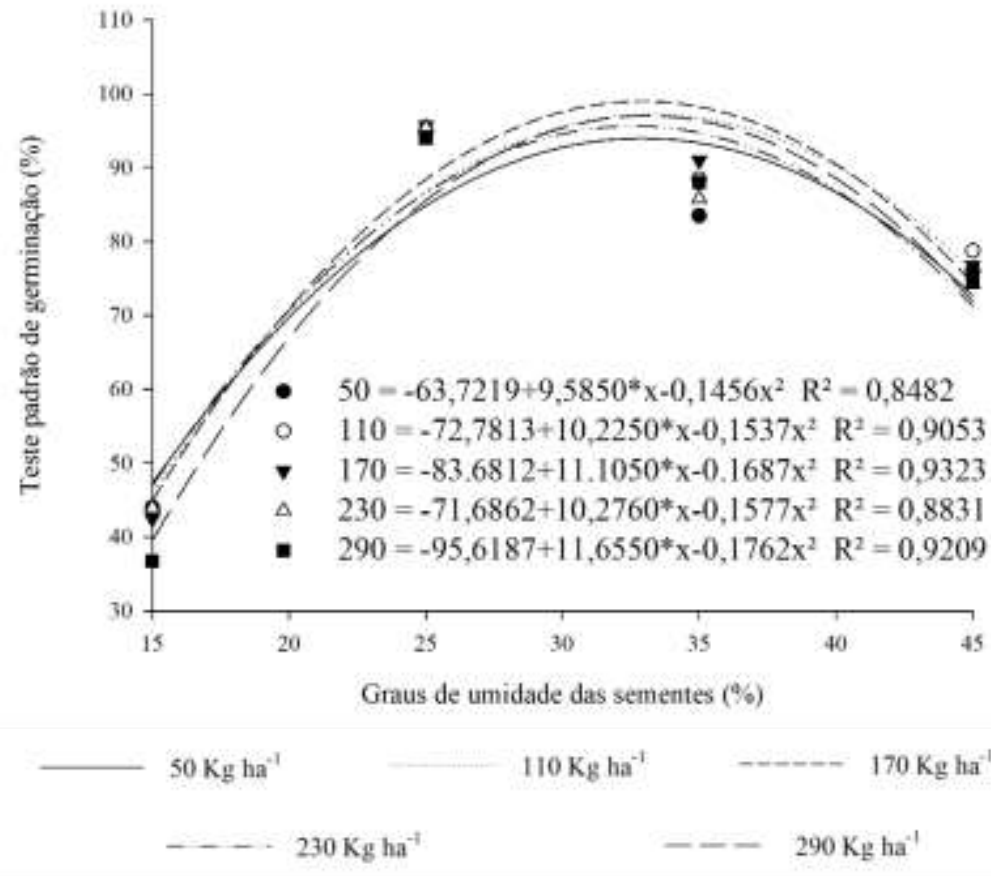

Fonte: Autores.

A Figura 10 mostra o resultado do peso de mil sementes (PMS) em relação aos graus de umidade das colheitas, com as sementes já submetidas à secagem a 13\%. Observa-se que as sementes colhidas aos $15 \%$ de b.u, quando submetidas à secagem a $13 \%$ de umidade, apresentaram peso de mil sementes maior em comparação com as sementes colhidas com $45 \%$ de umidade.

Figura 10. PMS com sementes de umidade corrigida a 13\% em relação aos graus de umidade das colheitas, semente submetidas ao processo da secagem. Ceres GO, 2019.

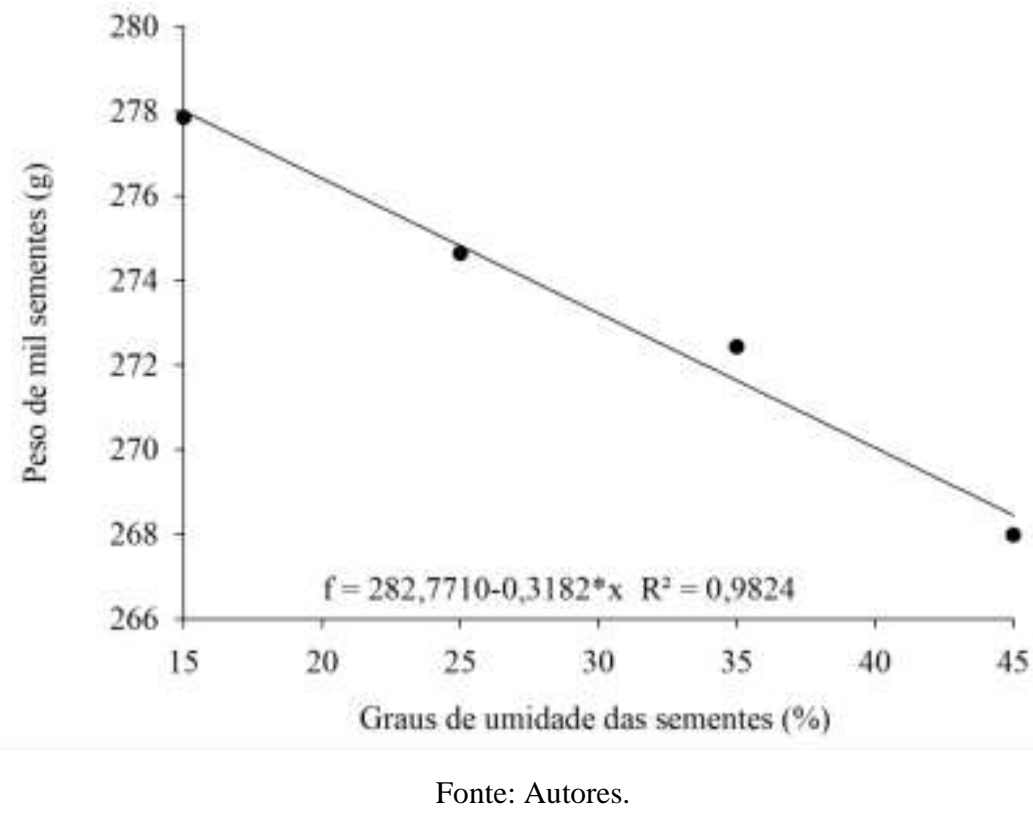


A Figura 11 mostra o resultado da condutividade elétrica (CE) em relação às doses de $\mathrm{N}$ e aos graus de umidade das colheitas com as sementes já submetidas à secagem. E observa-se que sementes colheitas com $45 \%$ de umidade, posteriormente passadas pelo processo de secagem, apresentaram resultado de condutividade elétrica maior.

Figura 11. CE com sementes de umidade corrigida a $13 \%$ em relação às doses de $\mathrm{N}$ e aos graus de umidade das colheitas submetidas ao processo da secagem. Ceres GO, 2019.

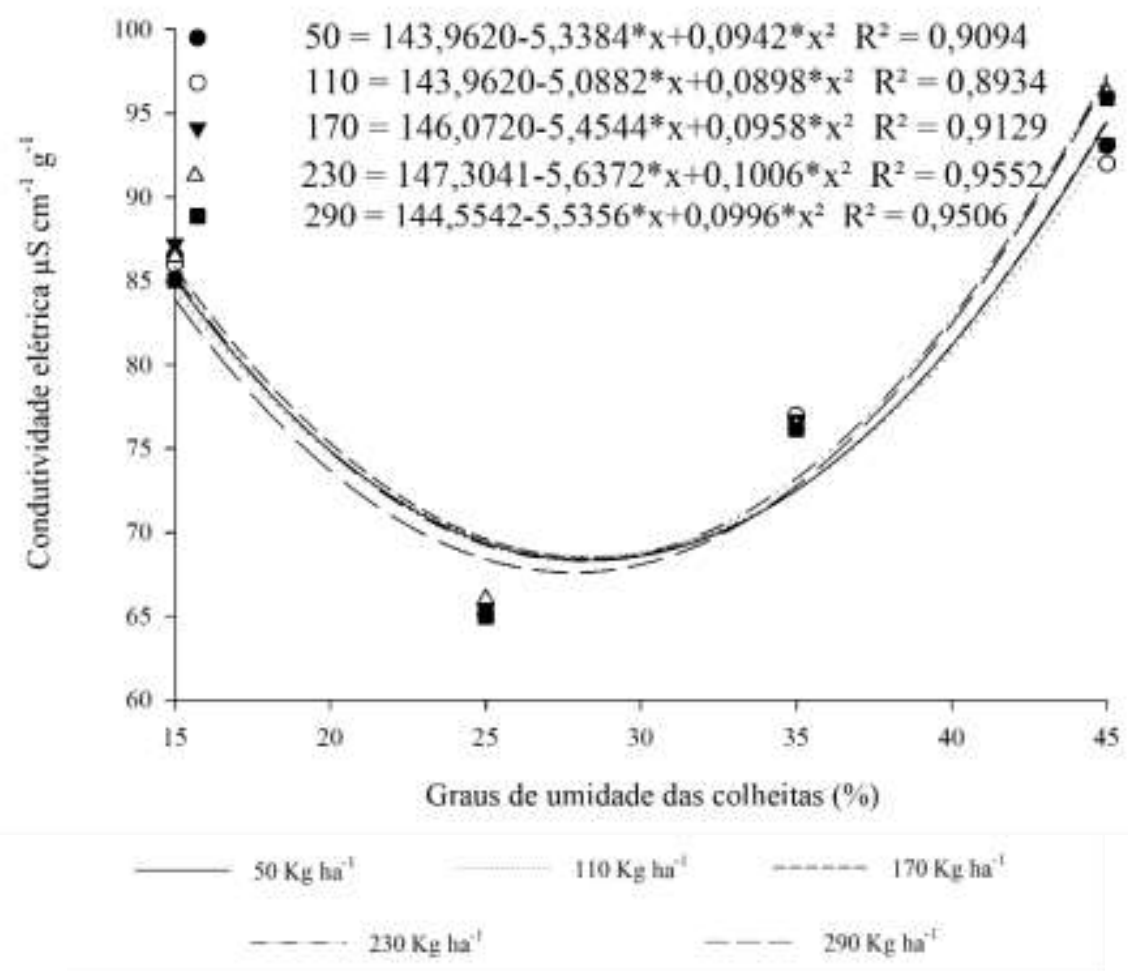

Fonte: Autores.

A Figura 12 mostra o resultado do teste de tetrazólio em relação às doses de $\mathrm{N}$ e aos graus de umidade das colheitas com as sementes já submetidas à secagem. Pode-se observar que as sementes com colheita a $25 \%$ de umidade, mesmo sendo submetidas à secagem a $13 \%$ de umidade, apresentaram resultado de vigor melhor. 
Research, Society and Development, v. 10, n. 9, e23410917144, 2021

(CC BY 4.0) | ISSN 2525-3409 | DOI: http://dx.doi.org/10.33448/rsd-v10i9.17144

Figura 12. TZ com sementes de umidade corrigida a $13 \%$ em relação às doses de $\mathrm{N}$ e aos graus de umidade das colheitas submetidas ao processo da secagem. Ceres GO, 2019.

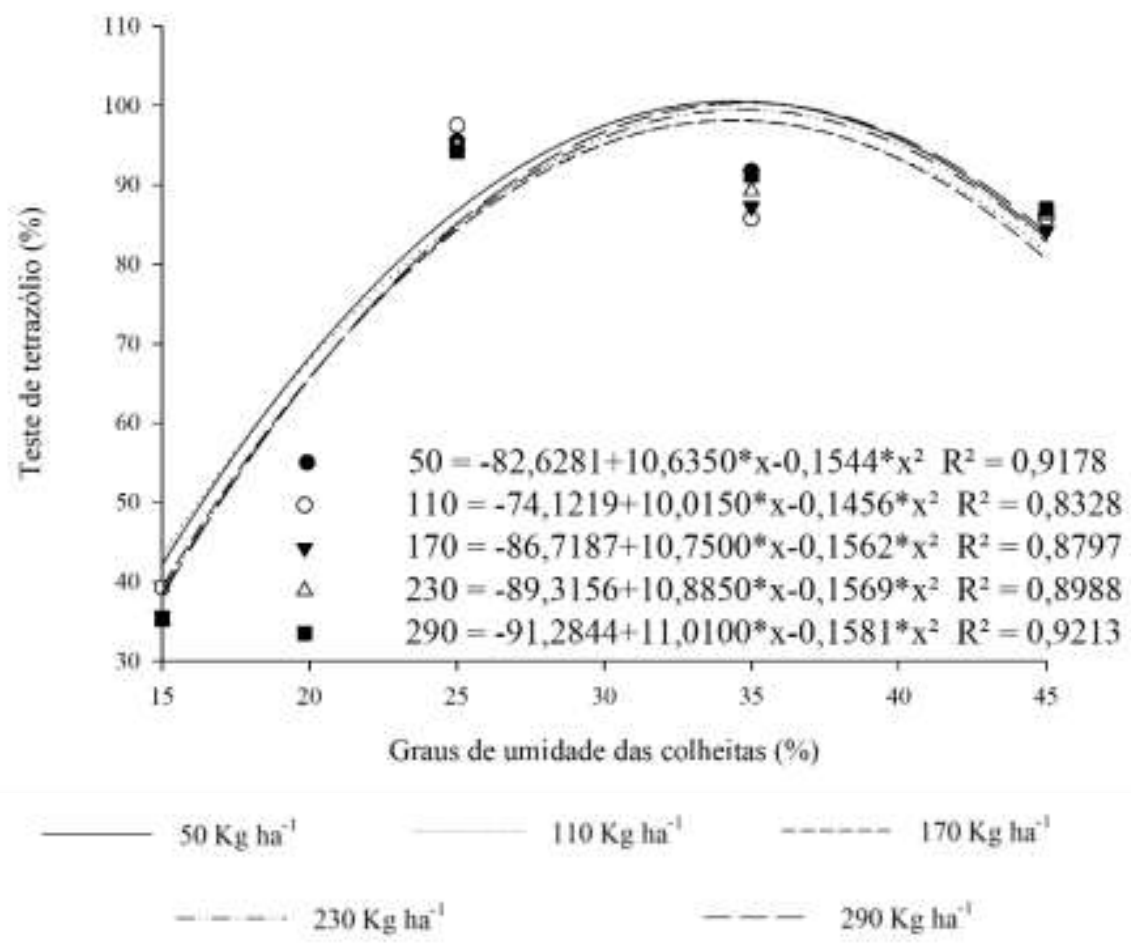

Fonte: Autores.

A Figura 13 mostra o resultado do envelhecimento acelerado em relação às doses de $\mathrm{N}$ e aos graus de umidade das colheitas com as sementes já submetidas à secagem a $13 \%$ de umidade. Como pode ser visto, as sementes colhidas com $25 \%$ de umidade obtiveram melhores resultados de envelhecimento acelerado. 
Research, Society and Development, v. 10, n. 9, e23410917144, 2021

(CC BY 4.0) | ISSN 2525-3409 | DOI: http://dx.doi.org/10.33448/rsd-v10i9.17144

Figura 13. EA com sementes de umidade corrigida a $13 \%$ em relação às doses de $\mathrm{N}$ e aos graus de umidade das colheitas, sementes submetidas ao processo da secagem. Ceres GO, 2019.

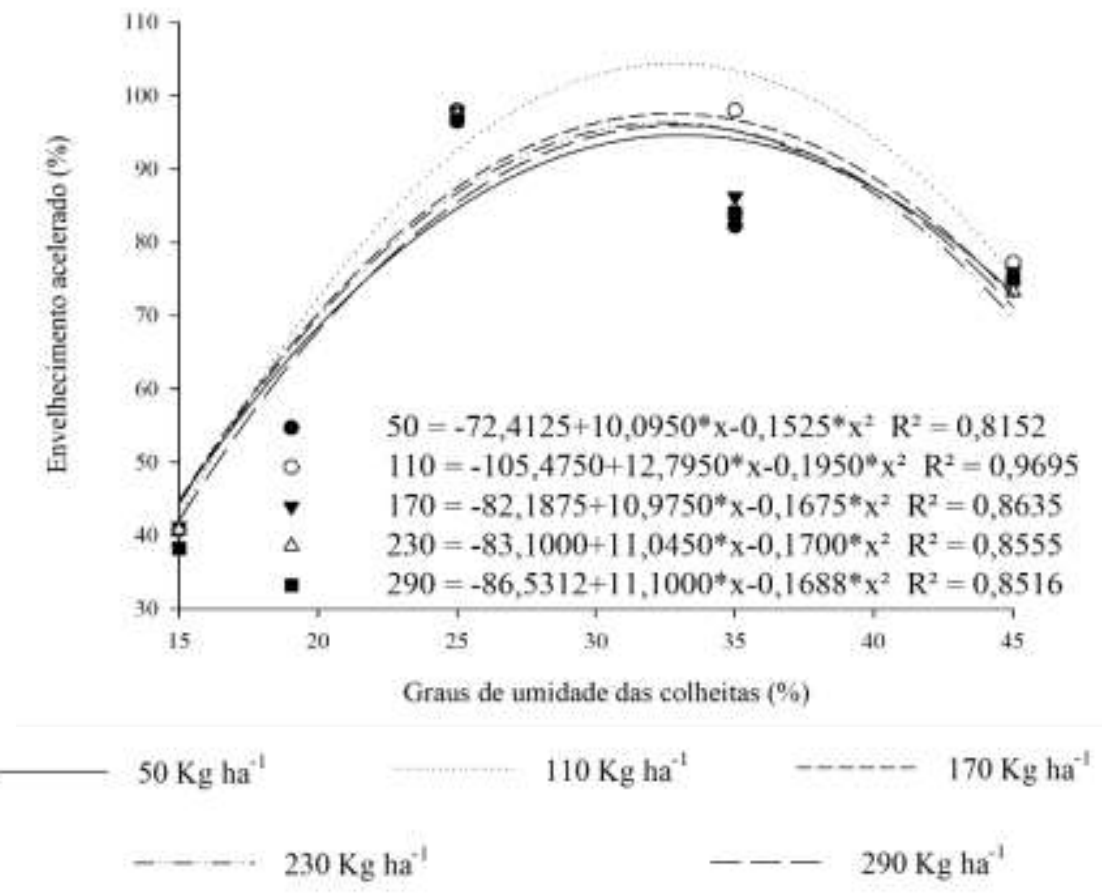

Fonte: Autores.

Observou-se que sementes colhidas com $15 \%$ de umidade, mesmo submetidas à secagem para chegar a 13\% de umidade, apresentaram alto teor de infestação. A Figura 14 mostra o resultado do canteiro em areia em relação às doses de $\mathrm{N}$ e aos graus de umidade das colheitas com as sementes já submetidas à secagem. As sementes colhidas com $25 \%$ de umidade apresentaram melhor resultado de emergência em canteiro de areia. 
Figura 14. CA com sementes de umidade corrigida a $13 \%$ em relação às doses de $\mathrm{N}$ e aos graus de umidade das colheitas submetidas ao processo da secagem. Ceres GO, 2019.

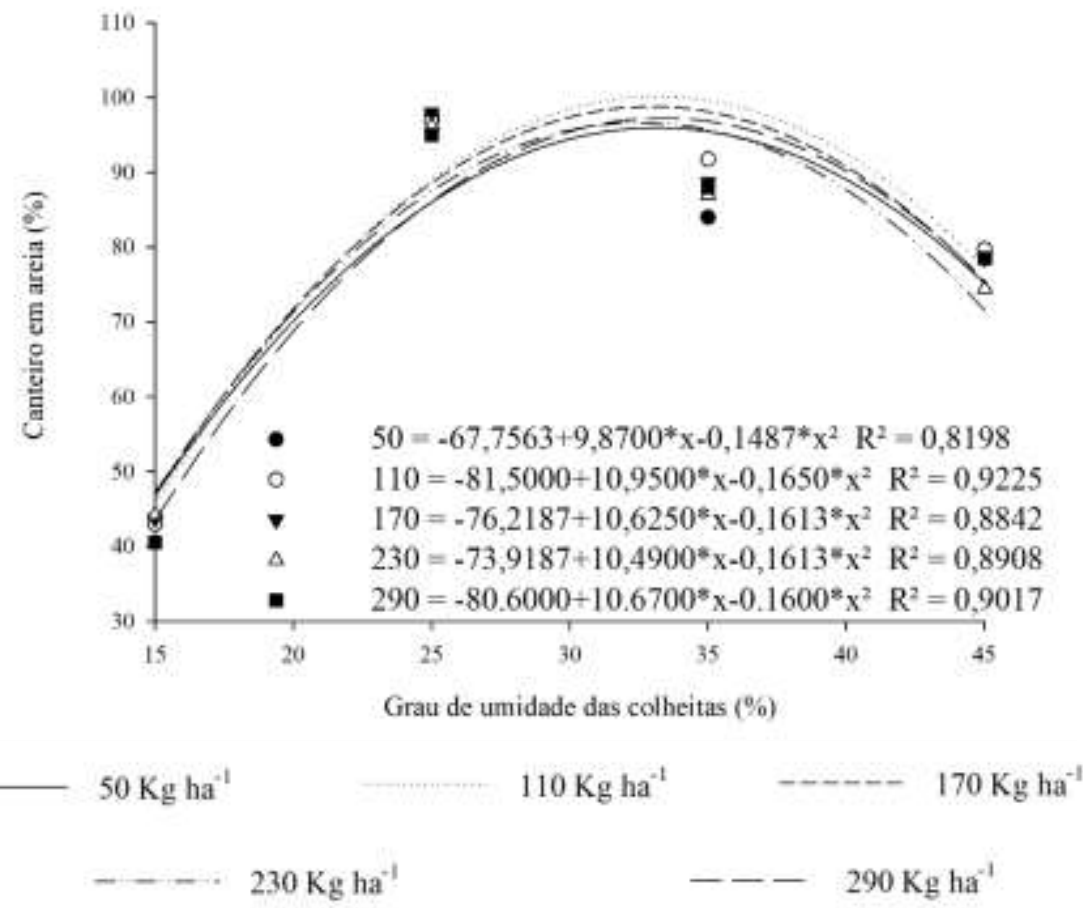

Fonte: Autores.

Na Figura 15 observa-se o resultado de produtividade, pois quanto mais alta a umidade ( $45 \%$ de umidade) das sementes, menor a produtividade, e quanto menor o grau de umidade (15\% de umidade), maior a produtividade.

Figura 15. Produtividade em relação aos graus de umidade das quatro colheitas, sementes com umidade a $13 \%$. Ceres GO, 2019.

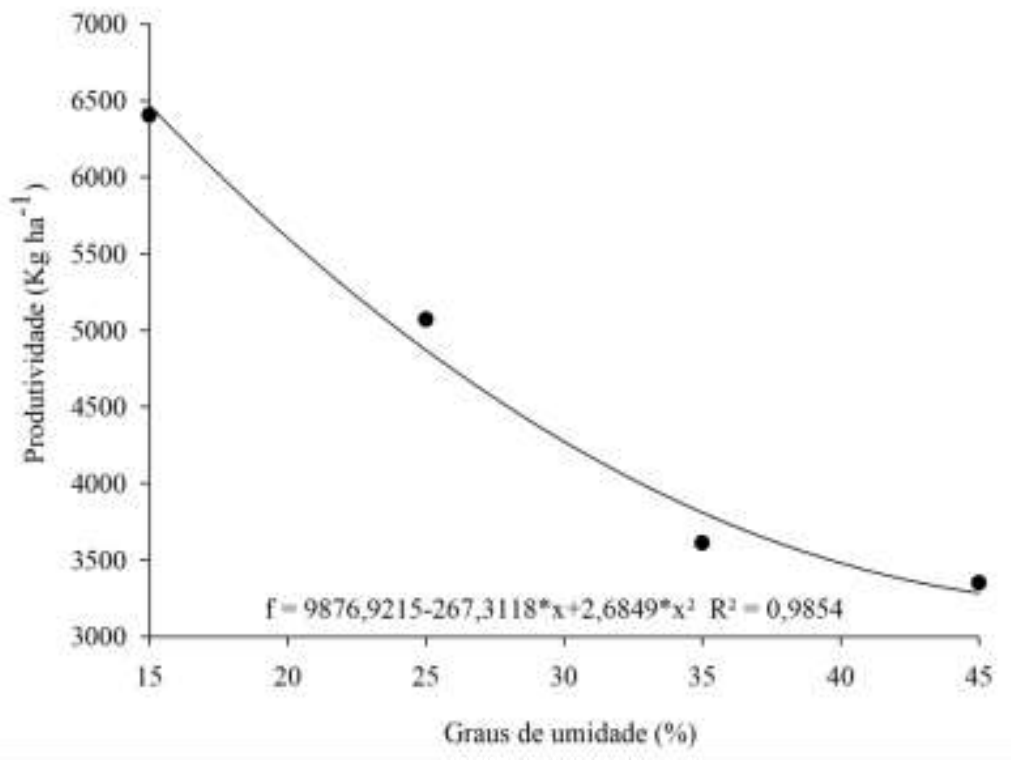

Fonte: Autores. 


\section{Discussão}

A linhagem de milho estudada neste trabalho foi responsiva ao aumento das doses de nitrogênio apenas quanto à altura de plantas, altura de inserção da primeira espiga e qualidade fisiológica de sementes, mas não quanto ao diâmetro do caule, conteúdo de nitrogênio na semente, comprimento e diâmetro de espigas, número de sementes por fileira, número de sementes por espiga, número de fileira e produtividade. Uma vez que não há estudos prévios do genótipo estudado, essas são observações inéditas que revelam seu comportamento de capacidade de resposta à baixa disponibilidade de nitrogênio, assim como de resposta ao aumento de nitrogênio no solo.

O incremento de nitrogênio no solo por fertilizantes químicos comumente promove melhorias no desenvolvimento de plantas e também de produção em genótipos comerciais de milho (Batista et al., 2019; Besen et al., 2020; Lins et al., 2020), no entanto, as diferentes cultivares têm graus diferentes de responsividade ao nitrogênio. Em se tratando de linhagens objeto deste trabalho, a variação de respostas de milho ao nitrogênio costuma ser ainda mais expressiva que entre as cultivares híbridas em função de menor interferência sobre as características herdadas de seus ancestrais (Liu et al., 2009; Abdel-Ghani et al., 2013; AlNagar et al., 2015).

Essa capacidade de resposta ao nitrogênio pode favorecer ou desfavorecer cruzamentos genéticos que resultem em cultivares comerciais por ser uma característica que pode ser transferida geneticamente (Lafitte \& Edmeades, 1995; Meseka et al., 2013; Kamara et al., 2014). Embora a maioria das linhagens de milho estudadas quanto à tolerância à baixa disponibilidade de nitrogênio tenham respostas bastante variáveis, assim como são variáveis quanto à capacidade de responder ao aumento de nitrogênio sobre aspectos de produção, há relato de linhagens que não apresentam nenhuma resposta em função do aumento de doses (Balko \& Russel, 1980), assim como observado neste estudo.

Além de aspectos de produção, as respostas de linhagens ao aumento de nitrogênio também podem ocorrer em relação a outros fatores, isolados ou combinados, como altura de planta, polinização, tempo necessário à reprodução, senescência foliar, arquitetura da planta, produção de biomassa, diâmetro de colmo, área foliar (Balko \& Russel, 1980; Bertin \& Gallais, 2000; D'Andrea et al., 2006), tal qual observado neste trabalho, com resposta de aumento apenas para altura de planta e de inserção da espiga.

Há de se salientar que o fato de não ter havido incremento de produtividade, na medida em que houve aumento das doses de nitrogênio, revela que o cultivo da linhagem estudada poderia ocorrer, sem prejuízo à produção, com a menor dose de $\mathrm{N}$ testada, $50 \mathrm{~kg} \mathrm{~N} \mathrm{ha}^{-1}$, o que diminuiria os custos de produção. Além do mais, produtividade superior a $6.000 \mathrm{~kg} \mathrm{ha}^{-1}$, como a observada neste trabalho, está em bom patamar em se tratando de linhagem (Menkir et al., 2004; Soares et al., 2011), o que evidencia que o genótipo em questão tem alta eficiência no uso de nitrogênio. Isso significa que o fato de uma linhagem não responder ao aumento de nitrogênio não implica, necessariamente, baixa eficiência de seu uso.

Ressalta-se ainda um crescente interesse por genótipos de milho que se desenvolvem e produzem bem em solos pobres em nitrogênio (Lafitte \& Edmeades, 1995), até mesmo porque o crescente empobrecimento de nitrogênio em áreas agricultáveis é um dos fatores considerados limitantes para a sustentabilidade humana, face aos recursos globais disponíveis (Steffen et al., 2015). Fatores que podem estar envolvidos na eficiência do uso de nitrogênio nas linhagens são o volume, massa, razão de massa de raiz/parte aérea e distribuição do sistema radicular, embora não tenham sido objeto de investigação do presente trabalho.

A influência de fatores hereditários sobre o desenvolvimento do sistema radicular foi considerada de média a alta, quando analisadas 74 linhagens de milho (Abdel-Ghani et al., 2013), tornando as raízes um fator de alta relevância em seleção de linhagens por ser uma característica passível de transferência às futuras cultivares comerciais (Meseka et al., 2013).

Analisando aspectos morfológicos, um sistema radicular desejado é aquele que propicia a exploração de maior área durante a aquisição de nutrientes, especialmente em ambientes com baixa disponibilidade de nitrogênio (Abdel-Ghani et al., 
2013). Liu et al. (2009), estudando duas linhagens de milho, uma muito responsiva ao nitrogênio e a outra pouco responsiva, observaram que a linhagem muito responsiva detinha maior volume de massa e de raízes e que essa grandeza do sistema radicular estava positivamente correlacionada com a produção.

Ao analisar a importância de um sistema radicular em genótipo pouco responsivo ao nitrogênio, mas com alta eficiência em seu uso, como a linhagem estudada neste trabalho, tal qual discutido acima, e sabendo que o tamanho que um sistema radicular pode atingir é uma característica influenciada pela genética, há de se considerar que outras características para além de volume, distribuição e massa radicular sejam importantes na aquisição de nitrogênio, de modo que o genótipo suporte a mesma produtividade ainda que com uma variação entre $290 \mathrm{~kg} \mathrm{~N} \mathrm{ha}^{-1}$ e $50 \mathrm{~kg} \mathrm{~N} \mathrm{ha}^{-1}$, como observado neste estudo.

Neste sentido, presume-se que a aquisição de nitrogênio também seja influenciada pela capacidade do genótipo em regular para mais ou para menos a absorção de íons nitrogenados através da atividade das proteínas transportadoras de membrana.

Considera-se que essa regulação possa contribuir com o armazenamento de alguns desses íons para uso futuro, suprindo os momentos de alta demanda da planta, assim como também que a planta seja capaz de diminuir a absorção excessiva de íons nitrogenados tóxicos, quando em abundância no solo, e assim evitar toxidez pela aquisição de íons que não podem ser armazenados em momentos em que já não haja suficiente aparato bioquímico para imediata assimilação.

É comum aumento na produção e na atividade de proteínas de transporte de $\mathrm{NO}_{3}{ }^{-}$e $\mathrm{NH}_{4}{ }^{+}$no sistema radicular, que são as formas iônicas nitrogenadas absorvíveis pelas raízes (Kusano et al., 2011), como resposta rápida ao aumento do nitrogênio no solo. No entanto, estudos comprovam que esse comportamento é distinto entre linhagens de milho (Gu et al., 2013; Zamboni et al., 2014).

Presume-se que esse rápido aumento de aquisição de nitrogênio, acima da demanda momentânea, ocorra como forma de prevenção à escassez, pelo fato de ser um nutriente muito dinâmico no solo, com perdas elevadas, ao mesmo tempo em que é necessário em grande quantidade para o crescimento vegetal. Para ambos os íons, são conhecidos transportadores de alta e de baixa afinidade.

Em condição de baixa disponibilidade de nitrogênio, espera-se aumento de síntese e de atividade de transportadores de alta afinidade, enquanto a atividade de transportadores de baixa afinidade necessita de alta disponibilidade de nitrogênio (Von Wirén et al., 2000).

Por outro lado, percebe-se uma rápida perda de atividade de transportadores, especialmente de alta afinidade, em plantas que ultrapassam um ótimo de suprimento de nitrogênio, como forma de reduzir a absorção (Glass, 2003) e, assim, evitar o efeito tóxico desses íons em altas concentrações na célula, sem que sejam imediatamente assimilados, especialmente em se tratando de um íon prontamente assimilável, o amônio (Glass et al., 2002).

Havendo excessiva quantidade de nitrogênio no solo e mais íons nitrogenados na célula do que a capacidade que as enzimas glutamina sintetase, glutamato sintase e aminotransferases conseguem assimilar, percebe-se uma rápida queda da atividade das proteínas responsáveis pela absorção, o que representa uma fina regulação entre as proteínas de assimilação e absorção (Lee et al., 1992). Para além dessa queda da atividade de absorção, também pode haver efluxo desses íons a partir das raízes, promovendo aumento de perdas econômicas, potencializando danos ambientais (Glass, 2003).

Considerando que estudos prévios têm observado alteração na aquisição de nitrogênio em função da atividade de proteínas de absorção entre linhagens, embora não investigado neste estudo, evidências fenotípicas permitem inferir sobre a capacidade de regular a aquisição de nitrogênio da linhagem estudada.

Ao considerar que o nitrogênio é um elemento fundamental à produção e que a linhagem utilizada neste trabalho teve produtividade elevada e inalterada entre tratamentos de 50 a $290 \mathrm{~kg} \mathrm{~N}^{-1}$, presume-se que tenha boa capacidade de aquisição de nitrogênio, mesmo na mais baixa dose testada. Isso denota boa regulação das proteínas envolvidas com a absorção, em que o número e a atividade daquelas de alta afinidade podem aumentar em condição de baixa disponibilidade de nitrogênio no solo. 
Observado aumento no crescimento das plantas em função do aumento de nitrogênio, presume-se também habilidade do genótipo em aumentar a atividade das proteínas de absorção em resposta rápida ao aumento de nitrogênio.

Ainda, o fato de que nenhum aspecto fenológico das plantas denotava toxidez por excesso de nitrogênio, mesmo no tratamento com $290 \mathrm{~kg} \mathrm{~N} \mathrm{ha}^{-1}$, evidencia boa regulação na atividade de proteínas de membrana, evitando absorção excessiva, acima da capacidade de assimilação. Essa evidência se fortalece ainda mais quando se analisa o potencial de toxidez do fertilizante utilizado neste estudo, a ureia.

A forma final de disponibilização de nitrogênio às plantas por esse fertilizante é o $\mathrm{NH}_{4}{ }^{+}$(Catani \& Bataglia, 1969), íon com alto potencial de toxidez e que, portanto, não pode ser armazenado pela célula, diferentemente de $\mathrm{NO}_{3}{ }^{-}$, disponibilizado por fertilizantes nítricos, que poderia ser armazenado com baixo potencial de dano à célula até certo limite de concentração (Fan et al., 2007). Ao considerar que não houve aumento de produtividade neste estudo, se este for o objetivo final do cultivo da linhagem, é possível concluir que altas doses de nitrogênio representam um desperdício, ou ainda um risco potencial de contaminação ambiental por conta de íons nitrogenados não aproveitados pela planta.

Além de a linhagem estudada não ser responsiva ao aumento de nitrogênio sobre a produção de sementes, ela também não foi responsiva ao aumento de nitrogênio total nas sementes. É comum o aumento na disponibilidade de nitrogênio no ambiente promover aumento no conteúdo de nitrogênio nos grãos (Thiraporn et al., 1992).

O fato de esse comportamento não ter sido observado neste estudo indica uma regulação em função do genótipo. Considerando a íntima relação entre o conteúdo de nitrogênio e o de proteína (AOAC, 1970; Tsai et al., 1983), é possível observar a importância do aspecto hereditário sobre o conteúdo destes compostos em grãos de milho em vários outros estudos (Uribelarrea et al., 2004; Flint-Garcia et al., 2009; Tsai et al.,1992), os quais relataram estreita relação entre a capacidade de acúmulo de proteína ou nitrogênio em grãos de genótipos específicos em função da capacidade genética de seus ancestrais.

Diversas pesquisas mostram que o conteúdo de nitrogênio ou de proteína nos grãos costuma aumentar na medida em que há aumento da disponibilidade de nitrogênio no ambiente (Tsai et al., 1983; Uribelarrea et al., 2004; Ohland et al., 2005; Riedell et al., 2009; Mendonça et al., 1999; Souza et al., 2016).

De acordo com Tsai et al. (1992), comumente, genótipos que respondem bem ao aumento de produção em função do aumento de nitrogênio costumam ter aumento de conteúdo proteico nos grãos. No caso do presente trabalho, não houve aumento de nitrogênio, tendo sido observado que o teor de nitrogênio total no grão ficou em torno de 1,5\% em todos os tratamentos.

É importante ressaltar que, embora a linhagem estudada não seja responsiva ao aumento de nitrogênio no solo quanto à produção e conteúdo de nitrogênio na cariopse, além de ter tido produtividade compatível com a de outras linhagens, como previamente abordado, também teve o teor de nitrogênio total nos grãos compatível com híbridos comerciais (Ohland et al., 2005; Lošák et al., 2010), o que é uma observação importante em se tratando de linhagem, ao almejar sua utilização em cruzamentos que visem à qualidade de grãos nas novas cultivares.

Além da qualidade de grãos, do ponto de vista de composição química, o nitrogênio também está envolvido na qualidade fisiológica de sementes de milho. De acordo com os resultados obtidos neste trabalho, o aumento de nitrogênio desencadeou alteração no percentual de germinação, quando analisados com o teste padrão e envelhecimento acelerado, emergência no canteiro de areia, o vigor, analisado por condutividade elétrica, e a viabilidade, analisada pelo teste do tetrazólio.

Estudos têm relacionado a qualidade fisiológica de sementes de milho ao aumento de nitrogênio no ambiente, sejam cultivares (Imolesi et al., 2001; Oliveira Gondim et al., 2006; Zucareli et al., 2012) ou linhagens (Imolesi et al., 2001). Tanto nas cultivares quanto nas linhagens, o aumento de nitrogênio induziu aumento ou diminuição de qualidade fisiológica, evidenciado por vários indicadores, o que mostra influência do genótipo em resposta ao nitrogênio sobre a qualidade de sementes.

Ao considerar a colheita feita com cariopses com $35 \%$ de umidade, período inicial da maturidade fisiológica do milho (Guiscem et al., 2002a; Santos, 2006), observou-se neste trabalho que doses de nitrogênios superiores a $170 \mathrm{~kg} \mathrm{~N} \mathrm{ha}^{-1}$ 
promoveram maior percentual de germinação tanto pelo teste padrão quanto pelo envelhecimento acelerado e canteiro de areia, indicando responsividade do genótipo ao aumento de nitrogênio para estas variáveis. Resposta similar foi observada quando as sementes foram submetidas à secagem a partir de $35 \%$ até $13 \%$ de umidade, percentual padrão de armazenamento (Santos, 2006).

Em outro estudo, o aumento de nitrogênio em nada alterou o percentual de germinação (Zucareli et al., 2012). Oliveira Gondim et al. (2006), estudando 14 genótipos de milho, observaram que todos tinham alta qualidade fisiológica de sementes quando cultivados com alta disponibilidade de nitrogênio, mas apenas três se mantiveram com alta qualidade sob baixa disponibilidade de nitrogênio, característica de interesse no âmbito do melhoramento genético.

Na pesquisa desenvolvida por Imolesi et al. (2001), fica evidente o efeito do genótipo sobre a qualidade fisiológica de sementes, tanto de híbridos quanto de linhagens, ao observarem que o aumento de nitrogênio, ao mesmo tempo em que provocava aumento de germinação em alguns genótipos, provocava diminuição em outros, enquanto outros genótipos eram indiferentes. No entanto, é importante destacar que nesta mesma pesquisa, entre nove genótipos, apenas um teve aumento de condutividade elétrica com o aumento de nitrogênio.

Além da influência do nitrogênio, o estudo do percentual de umidade de colheita sobre aspectos de qualidade de sementes se faz importante para linhagens, uma vez que o objetivo de seu cultivo é exatamente produzir sementes de boa qualidade para uso reprodutivo. O momento ideal para a colheita de milho, visando ao rendimento e à qualidade, é após a maturação fisiológica, com melhor desempenho entre 22 e $26 \%$ (Galindo et al., 2017), desde que seja rapidamente dessecado até em torno de 13\% de umidade antes do armazenamento (Santos, 2006).

No entanto, nem todos os produtores têm acesso a dessecadores, necessitando manter as espigas no campo para dessecamento natural, e nem sempre a logística permite rapidez entre a colheita e o dessecamento forçado. A existência dessas situações, somadas a possíveis variações entre o teor de umidade e a maturidade fisiológica em diferentes genótipos (Guiscem et al., 2002b), justifica uma análise de qualidade fisiológica das sementes quando as cariopses são colhidas em diferentes graus de umidade e também quando dessecadas a partir de diferentes graus de umidade ao percentual de armazenamento.

Ao analisar o percentual de germinação em diferentes graus de umidade, percebe-se que foi no teor de $45 \%$ que ocorreu o mais baixo percentual, seja em teste padrão, pelo envelhecimento acelerado ou emergência em canteiro de areia, o que evidencia uma maturidade fisiológica ainda não atingida, não estando as sementes prontas para o metabolismo germinativo, muito embora já seja um momento de alto acúmulo de massa.

Considera-se que neste percentual de umidade as sementes ainda tenham uma alta supressão à germinação positivamente regulada pelo ácido abscísico, efeito este que perde força à medida que aumenta naturalmente o grau de dessecação, favorecendo a germinação pela ação da giberelina. Esta evidência se fortalece ao se observar que genótipos de milho deficientes em ácido abscísico germinam precocemente, antes de atingir a maturidade fisiológica (White et al., 2000).

A dessecação, no entanto, desfavorece a ação do ácido abscísico e, consequentemente, favorece a ação de enzimas envolvidas com o metabolismo germinativo como a $\alpha$-amilase (Oishi \& Bewley, 1990), o que se evidencia neste presente trabalho ao observar que ocorreu elevado aumento nos percentuais de geminação em teores de umidade inferiores a $45 \%$ e também ao dessecar as sementes de $45 \%$ para $13 \%$ de umidade.

O percentual de germinação a 35\% de umidade foi onde ocorreu maior efeito do teor de nitrogênio sobre a germinação, tendo a adubação nitrogenada acima de $170 \mathrm{~kg} \mathrm{~N} \mathrm{ha}^{-1}$ favorecido os maiores percentuais, seja pelo teste padrão, envelhecimento acelerado ou pela emergência em canteiro de areia.

Em estudo prévio com linhagens de milho, Limami et al. (2002) observaram que o conteúdo de glutamina e/ou a atividade de glutamina sintetase aumentam durante a germinação e que a glutamina pode se comportar como um dreno para o amônio resultante de hidrólise proteica ou de desaminação e ainda que a atividade da enzima favorece a síntese de glutamina a ser utilizada na formação de vários outros aminoácidos necessários ao desenvolvimento da plântula. 
Considerando que o adubo utilizado neste estudo disponibiliza nitrogênio na forma de amônio, presume-se que maiores doses de nitrogênio tenham favorecido a ação da glutamina sintetase, favorecendo a germinação. No entanto, houve redução do efeito do teor de nitrogênio sobre o percentual de germinação quando testado o grau de umidade de $15 \%$ e também quando as cariopses foram dessecadas a 13\% a partir de diferentes graus de umidade, o que fortalece ainda mais a evidência da ação da glutamina sintetase, uma vez que é uma enzima que tem atividade reduzida à medida que se diminui o conteúdo de água nos tecidos (Li et al., 2017). O percentual de germinação com grau de umidade a 15\%, seja utilizando o teste padrão, o envelhecimento acelerado ou emergência em canteiro, ou cariopses dessecadas a 13\%, foi o menor em comparação com os demais graus de umidade dentro do período de maturação fisiológica. Esta resposta mostra que o dessecamento natural a campo ou a demora para colheita e dessecação, após a maturação fisiológica, poderia causar expressiva perda de qualidade fisiológica da semente.

Essas perdas podem ser decorrentes de vários fatores, incluindo danos causados por infestações, insolação, ventos, temperatura, pássaros e chuvas (Santos, 2006). Como era de se esperar, percebe-se uma relação direta entre esse baixo percentual de germinação a 15\% de umidade e o menor vigor, denotado pela alta condutividade elétrica, e menor viabilidade, denotada pelo teste do tetrazólio. A viabilidade de sementes depende naturalmente da integridade física de células e tecidos, podendo ser evidenciada pela condutividade elétrica. Maior condutividade significa maior número de eletrólitos, derivados de lixiviação decorrente de danos físicos nas células. Em se tratando de células vegetais de fanerógamas, portanto, eucarióticas, a homeostase celular depende muito da integridade das membranas (Blazek et al., 2015), permitindo, assim, atividades metabólicas não compatíveis ocorrendo ao mesmo tempo em diferentes compartimentos celulares isolados por biomembranas.

O vigor da semente, consequentemente, também depende dessa integridade física. A secagem, seja natural ou artificial, é um dos fatores que podem elevar os danos físicos das membranas em decorrência de impactos mecânicos, aumentando processos como peroxidação de lipídeos e estresse oxidativo celular (Pérez-Rodríguez et al., 2017; Pagano et al., 2019), acelerando, portanto, a morte e a perda de viabilidade.

Limites de secagem e técnicas adequadas são, portanto, fundamentais para a preservação da integridade física e da qualidade das sementes. Outro fator importante que pode levar a célula à morte é a temperatura à qual a semente é exposta durante a secagem, uma vez que altas temperaturas também podem desencadear estresse oxidativo (Liu et al., 2019). A capacidade de as linhagens tolerarem altas temperaturas, com atenuação de consequências indesejáveis, é um fator relevante, pois é um caráter analisado com base em proteínas de choque térmico, passível de transmissão a futuras gerações (José et al., 2004).

O alto percentual de sementes infestadas, tomando como base Almeida et al. (2012), observado neste trabalho, pode ter sido favorecido pelas intempéries do ambiente, incluindo alta insolação e chuvas que ocorreram durante o dessecamento a campo. A maior infestação observada em grãos dessecados a 13\%, comparativamente aos de 15\%, é outra evidência que fortalece a ideia de aumento de danos físicos ocorridos durante a dessecação.

Os tratamentos que tiveram melhores percentuais de germinação foram exatamente aqueles em que foram observadas as menores condutividades elétricas e a maior reação com o tetrazólio, sementes com 25 e $35 \%$ de umidade, e também quando a partir dessas umidades foram dessecadas até $13 \%$. No entanto, o rendimento produtivo foi maior no percentual de $15 \%$ de umidade, indicando que o maior rendimento quantitativo nem sempre está relacionado à melhor qualidade fisiológica.

A perda ou ganho de produção em função do teor de água no grão no momento da colheita é tido como um fator característico do genótipo (Gambín et al., 2007; Galindo et al., 2017) ou da interação poligênica genótipo x ambiente (Schimildt et al., 2011), resultando em uma relação entre o acúmulo de biomassa em função do grau de umidade da cariopse (Gambín et al., 2007). Considerando essa premissa, a linhagem estudada no presente trabalho tem alta capacidade de continuar o acúmulo de biomassa nas sementes, mesmo com baixos conteúdos de água. Isso se revela ao se observar que o maior peso de 1.000 sementes 
dessecadas a $13 \%$ foi daquelas com $15 \%$ de umidade, e também a maior produtividade ocorreu no tratamento com grau de umidade de $15 \%$, enquanto, para outros genótipos, a umidade de grãos no momento da colheita que melhor se traduziu em produtividade variou de 22 a 26\% (Galindo et al., 2017), com aumento potencial de perda de massa por atividade respiratória quando a colheita é feita com menos de $18 \%$ de umidade (Marques et al., 2011).

Considerando que o cultivo de linhagem visa a aspectos reprodutivos, a qualidade fisiológica de sementes se sobrepõe ao rendimento produtivo. Neste caso, a colheita feita entre 25 e $35 \%$ de umidade, posteriormente passada pelo processo de secagem ou não a $13 \%$, correspondeu às umidades que propiciaram melhor qualidade de sementes.

O sistema de irrigação por gotejamento adotado no presente trabalho traz resultados positivos. Boas et al. (2011) afirmam que o sistema de irrigação por gotejamento apresenta vantagens, entre elas maior eficiência na adubação, uso de água e maior produtividade. A irrigação por gotejamento juntamente com parcelamentos em cobertura propicia resultados promissores. Souza et al. (2016) enfatizam o uso da irrigação localizada por gotejamento associado à nutrição mineral de plantas.

\section{Considerações Finais}

A linhagem estudada tolera baixa disponibilidade de nitrogênio, tem alta eficiência no seu uso e é pouco responsiva ao seu aumento no solo, mantendo as variáveis de produção e de conteúdo de nitrogênio na cariopse em alto patamar, mas sem variação significativa com oferta de 50 a $290 \mathrm{~kg} \mathrm{~N} \mathrm{ha}^{-1}$, respondendo positivamente ao aumento das doses apenas em altura das plantas.

Evidências fenológicas e de produção denotam suficiente eficiência regulatória quanto à aquisição de nitrogênio do solo. A linhagem responde positivamente ao aumento de nitrogênio no percentual de germinação, com melhores resultados acima de $170 \mathrm{~kg} \mathrm{~N} \mathrm{ha}^{-1}$. A secagem das sementes a 13\%, a partir do elevado grau de umidade de $45 \%$, favorece expressivo aumento de mais de $70 \%$ no percentual de germinação, indicando alta plasticidade do metabolismo germinativo.

A linhagem tem alta capacidade de acúmulo de biomassa nas cariopses mesmo com baixo teor de umidade, de tal modo que os maiores valores das variáveis de produção, peso de grãos e produtividade, ocorreram quando a colheita foi feita com grãos contendo $15 \%$ de umidade, dessecados ou não.

O grau de umidade da cariopse de $15 \%$ durante a colheita é o que melhor propicia rendimento produtivo, não correspondendo ao que melhor propicia qualidade fisiológica de sementes, 25 e $35 \%$, quando foram observadas as menores condutividades elétricas, maior reação com o tetrazólio e maiores percentuais de germinação com teste padrão, envelhecimento acelerado e emergência em canteiro de areia, com ou sem dessecamento a $13 \%$.

Considerando uma linhagem, foram observadas características desejáveis e passíveis de transmissão genética, como alta tolerância à baixa disponibilidade de nitrogênio, adequada regulação da aquisição de nitrogênio, adequado conteúdo de nitrogênio nas cariopses, resposta positiva ao nitrogênio quanto ao percentual de germinação e capacidade de acúmulo de biomassa em grãos com baixo teor de umidade.

Recomenda-se aplicar a dose $170 \mathrm{~kg}$ de nitrogênio, parcelada em quatro vezes, para adubação em cobertura da linhagem de milho estudada neste trabalho.

\section{Referências}

Abdel-Ghani, A. H, Kumar, B., Reyes-Matamoros, J., Gonzalez-Portilla, P., Jansen, C., Martin, J. P. S. \& Lubberstedt, T. (2013). Genotypic variation and relationships between seedling and adult plant traits in maize (Zea mays L.) inbred lines grown under contrasting nitrogen levels. Euphytica, 189 , $123-133$.

Ahlgren, S., Baky, A., Bernesson, S., Nordberg, A., Norén, O. \& Hansson, P.A. (2008). Ammonium nitrate fertilizer production based on biomass environmental effects from a life cycle perspective. Bioresource Technology, 99(17),8034-8041.

Ahrens, D. C., Barros, A. S. R., Villela, F. A \& Lima, D. (1998). Qualidade de sementes de milho (Zea mays L.) sob condições de secagem intermitente. Scientia Agricola, 55(2), 320-325. 
Research, Society and Development, v. 10, n. 9, e23410917144, 2021

(CC BY 4.0) | ISSN 2525-3409 | DOI: http://dx.doi.org/10.33448/rsd-v10i9.17144

Almeida, F. A. C., Silva Júnior, P. J., Silva, J. F., Lino, T. F. L. \& Silva, R. G. (2012). Infestação e germinação em sementes de milho tratadas com extratos de Piper nigrum e Annona squamosa. Revista Brasileira de Produtos Agroindustriais, 14, 457-471.

Al-Naggar, M. M., Shabana, R., Atta, M. M. M \& Al-Khalil, T. H. (2015) Regression of Grain Yield of Maize Inbred Lines and Their Diallel Crosses on Elevated Levels of Soil-Nitrogen. International Journal of Plant \& Soil Science, 4(6), 499-512.

Alves, B. M., Cargnelutti Filho, A., Toebe, C. B. M. \& Silva, L. P. (2015). Divergência genética de milho transgênico em relação à produtividade de grãos e da qualidade nutricional. Revista Ciência Rural, Santa Maria, 45(5), 884-891.

Alves, W. M., Faroni, L. D., Queiroz, D. M., Corrêa, P. C \& Galvão, J. C. C. (2001). Qualidade dos grãos de milho em função da umidade de colheita e da temperatura de secagem. Revista Brasileira de Engenharia Agrícola e Ambiental, 5(3),469-474.

AOAC - Association of Official and Agricultural Chemistry. (1970). Official methods of analysis of the AOAC

Arruda, M. R., Moreira, A \& Pereira, J. C. R. (2014). Amostragem e cuidados na coleta de solo para fins de fertilidade. Embrapa Amazônia Ocidental. Documentos $115.18 \mathrm{p}$.

Balko, L. G \& Russell, W. A. (1980). Response of Maize Inbred Lines to N Fertilizer 1. Agronomy Journal, 72(5),723-728.

Batista, V. V., Oligini, K. F., Giaretta, R., Rabelo, P. R., Adami, P. F \& Link, L. (2019). Densidade de plantas e doses de nitrogênio no cultivo de milho safrinha no Paraná. Agrarian, 12(45), 296-307.

Bertin, P. \& Gallais, A. (2000). Genetic variation for nitrogen use efficiency in a set of recombinant maize inbred lines. I. Agrophysiological results. Maydica, 45(1), 53-66.

Besen, M. R., Ribeiro, R. H., Goetten, M., Fioreze, S. L., Guginski-Piva, C. A \& Piva, J. T. (2020). Produtividade de milho e retorno econômico em sistema integrado de produção com doses de nitrogênio. Revista de Ciências Agroveterinárias, 19(1), 94-103.

Blazek, A. D., Paleo, B. J. \& Weisleder, N. (2015). Plasma membrane repair: a central process for maintaining cellular homeostasis. Physiology, 30(6), 438448.

Boas, R. C. V., Pereira, G. M., Reis, R. P., Júnior, J. A. L \& Consoni, R. (2011). Viabilidade econômica do uso do sistema de irrigação por gotejamento na cultura da cebola. Ciência e Agrotecnologia, 35, 781-788.

Bono, J. A. M., Rodrigues, A. P. D. C., Mauad, M., Albuquerque, J. C., Yamamoto, C. R., Chermouth, K. S \& Freitas, M. E. (2008). Modo de aplicação de fertilizantes nitrogenados na qualidade fisiológica de sementes de milho. Agrarian, 1(2), 91-102.

Borges, I. D. (2003). Avaliação de épocas de aplicação da cobertura nitrogenada, fontes de nitrogênio e de espaçamento entre fileiras na cultura do milho. Lavras-MG: Universidade Federal de Lavras (UFLA),73p. Dissertação Mestrado.

Brooker, D. B., Bakker-Arkema, F. W \& Hall, C. W. (1992). Drying and storage of grains and oilseeds. New York: van Nostrand Reinhold, 450p.

Catani, R. A \& Bataglia, O. C. (1969). A determinação direta do nitrogênio nítrico, amoniacal e amídico (uréia) em fertilizantes. Esc. Super. Agric. Luiz de Queiroz, 9-19.

Comissão de Fertilidade de Solos de Goiás. (1988). Recomendações de corretivos e fertilizantes para Goiás. $5^{a}$ Aproximação. UFG/EMGOPA. 101p. (Convênio. Informativo Técnico, 1).

CONAB - Companhia Nacional de Abastecimento. Acompanhamento da safra brasileira. (2019a) v.6. - Safra 2018/2019, n.10 - Décimo levantamento. Brasília: CONAB. https://www.conab.gov.br/info-agro/safras/graos.

CONAB - Companhia Nacional de Abastecimento. Acompanhamento da safra brasileira de grãos, $6^{\circ}$ levantamento, março. (2019b). http://www.conab.gov.br

Cruz, J. C., Pereira Filho, I A. P., Alvarenga, R. C., Gontijo Neto, M. M., Viana, J. H. M., Oliveira, M. F., Matrangolo, W. J. R. \& Albuquerque Filho, M. R. (2010). Cultivo do milho. 6ed. Sete Lagoas: Embrapa Milho e Sorgo.

Cunha, D. A., Coelho, A. B., Féres, J. G., Braga, M. J. \& Souza, E. C. (2013). Irrigação como estratégia de adaptação de pequenos agricultores às mudanças climáticas: aspectos econômicos. Revista de Economia e Sociologia Rural, 51(2)369-386.

D'Andrea, K. E., Otegui, M. E., Cirilo, A. G \& Eyherabide, G. (2006). Genotypic variability in morphological and physiological traits among maize inbred lines nitrogen responses. Crop science, 46(3), 1266-1276.

DoVale, J. C., Fritsche-Neto, R., Bermudez, F \& Miranda, G. V. (2012). Efeitos gênicos de caracteres associados à eficiência no uso de nitrogênio em milho. Pesquisa Agropecuária Brasileira, 47(3),385-392.

Eck, H. U. Effects of water deficit on yield components, and water use efficiency of irrigated corn. (1986). Agronomy Journal, 75, 1035-1040.

Estrela, C. (2018). Metodologia científica:ciência, ensino, pesquisa. Artes Médicas.

Fan, X,. Jia, L., Li, Y., Smith, S. J., Miller, A. J \& Shen, Q. (2007). Comparing nitrate storage and remobilization in two rice cultivars that differ in their nitrogen use efficiency. Journal of experimental Botany, 58(7), 1729-1740.

Flint-Garcia, S. A., Bodnar, A. L. \& Scott, M. P. (2009). Wide variability in kernel composition, seed characteristics, and zein profiles among diverse maize inbreds, landraces, and teosinte. Theor Appl Genet, 119, 1129-1142. 
França Neto, J. B., Krzyzanowski, F. C. \& Henning, A. A. (2010). A importância do uso de semente de soja de alta qualidade. Informativo técnico, EMBRAPA. $2 \mathrm{p}$.

Galindo, F. S., Zocoler, J. L., Teixeira Filho, M. C. M., Santini, J. M. K., Ludkiewicz, M. G. Z \& Buzetti, S. (2017). Teor de água nos grãos, em ocasião de colheita nas perdas ocorridas no milho. Revista de Ciências Agronômicas, 26(4), 671-682.

Galvão, J. C. C., Borém, A. \& Pimentel, M. A. (2015). Milho: do plantio a colheita. Editora UFV, 351p.

Gambín, B. L., Borrás, L \& Otegui, M. E. (2007). Kernel water relations and duration of grain filling in maize temperate hybrids. Field Crops Research, 101(1) $1-9$.

Glass, A. D. (2003). Nitrogen use efficiency of crop plants: physiological constraints upon nitrogen absorption. Critical reviews in plant sciences, 22(5),453470 .

Glass, A. D. M., Britto, D. T., Kaiser, B. N., Kinghorn, J. R., Kronzucker, H. J., Kumar, A., Okamoto, M., Rawat, S., Siddiqi, M. Y., Unkles, S. E. \& Vidmar, J. J. (2002). The regulation of nitrate and ammonium transport systems in plants. Journal of Experimental Botany, 53, 855-864.

Gomes, G. P. (2019). Influência de gotejadores com saída de água tipo fenda e cilíndrica na intrusão radicular em irrigação subsuperficial na cultura do milho. Botucatu-SP: Universidade Estadual Paulista - UNESP, 68p. Tese Doutorado.

Greaves, G. E \& Wang, Y. M. (2017). Effect of regulated deficit irrigation scheduling on water use of corn in southern Taiwan tropical environment. Agricultural Water Management, 188, 115-125.

Gu, R., Duan, F., An, X., Zhang, F., Wirén, N.V \& Yuan, L. (2013). Characterization of AMT-Mediated High-Affinity Ammonium Uptake in Roots of Maize (Zea mays L.). Plant Cell Physiol, 54(9), 1515-1524.

Guiscem, J. M., Bicudo, S.J., Nakagawa, J., Zanotto, D., Sansígolo, C., Zucarelli, C. \& Pavan, G. (2002b). Características morfológicas e fisiológicas do milho que influenciam a perda de água do grão. Revista Brasileira de Milho e Sorgo, 1(2), 28-37.

Guiscem, J. M., Nakagawa, J. \$ Zucareli, C. (2002a). Qualidade fisiológica de sementes de milho-doce br 400 (bt) em função do teor de água na colheita e da temperatura de secagem. Revista Brasileira de Sementes, 24(1), 220-228.

Imolesi, A. S., Pinho, E. V. R. V., Pinho, R. G. V., Vieira. M. G. G. C. V \& Corrêa, R. S. B. (2001). Influência da adubação nitrogenada na qualidade fisiológica das sementes de milho. Ciência e agrotecnologia, 25(5), 1119-1126.

José, S. C. B. R., Pinho, E. V. R., Pinho, R. G. ; Ramalho, M. A. P \& Silva Filho, J. L. (2004). Controle genético da tolerância à alta temperatura de secagem em sementes de milho. Revista Brasileira de Milho e Sorgo, 3, 414-428.

Kamara, M. M., El-Degwy, I. S \& Koyama, H. (2014). Estimation combining ability of some maize inbred lines using line x tester mating design under two nitrogen levels. Australian Journal of Crop Science, 8(9), 1336-1342.

Kjeldahl, J. Z. (1883). A new method for the determination of nitrogen in organic bodies. Analytical Chemistry, 2, $366-382$.

Kusano, M., Fukushima, A., Redestig, H. \& Saito, K. (2011). Metabolomic approaches toward understanding nitrogen metabolism in plants, Journal of Experimental Botany, 62(4), 1439-1453.

Lafitte, H. R \& Edmeades, G. O. (1995) Association between traits in tropical maize inbred lines and their hybrids under high and low soil nitrogen. Maydica, 40, 259-267.

Lee, R. B., Purves, J. V., Ratcliffe, R. G \& Saker, L. R. (1992). Nitrogen assimilation and the control of ammonium and nitrate absorption by maize roots. Journal of Experimental Botany, 43(11), 1385-1396.

Li, G \& Zhao, B \& Dong, S \& Zhang, J \& Liu, P \& Vyn, T. J. (2017). Interactive Effects Of Water And Controlled Release Urea On Nitrogen Metabolism, Accumulation, Translocation, And Yield In Summer Maize. Sci Nat., 104(72), 1-12.

Limami, A. M., Rouillon, C., Glevarec, G., Gallais, A. \& Hirel, B. (2002). Genetic and physiological analysis of germination efficiency in maize in relation to nitrogen metabolism reveals the importance of cytosolic glutamine synthetase. Plant Physiology, 130(4), 1860-1870.

Lins, F. J. A., Ferreira, P. V., Silva, M. T., Lira, R. C., Costa, J. G., Teixeira, J. S., Santos, N. E. A \& Pereira, M. G. (2020). Doses de nitrogênio na produção de grãos de genótipos de milho em superadensamento. Brazilian Journal of Development. 6(.3), 14879-14892.

Liu, J., Chen, F., Olokhnuud, C., Glass, A.D.M., Tong, Y., Zhang, F. \& MI, G. (2009). Root size and nitrogen-uptake activity in two maize (Zea mays) inbred lines differing in nitrogen-use efficiency. Journal of Plant Nutrition and Soil Science, 172(2), 230-236.

Liu, J., Hasanuzzaman, M., Wen, H., Zhang, J., Peng, T., Sun, H \& Zhao, Q. (2019). High temperature and drought stress cause abscisic acid and reactive oxygen species accumulation and suppress seed germination growth in rice. Protoplasma, 256(5), 1217-1227.

Lošák, T., Hlušek, J., Filipčík, R., Pospíšilová, L., Maňásek, J., Prokeš, K. \& Orosz, F. (2010). Effect of nitrogen fertilization on metabolisms of essential and non-essential amino acids in field-grown grain maize (Zea mays L.). Plant, Soil and Environment, 56(12), 574-579.

Marques, O. J., Dalpasquale, V. A., Vidigal Filho, P. S., Scapim, C. A \& Reche, D. L. (2011). Danos mecânicos em grãos de híbridos comerciais de milho em função da umidade de colheita. Semina: Ciências Agrárias, 32(2), 565-576.

Mendonça, F. C., Medeiros, R. D., Botrel, T. A \& Frizzone, J. A. (1999). Adubação nitrogenada do milho em um sistema de irrigação por aspersão em linha. Scientia Agricola, 56(4), 1035-1044. 
Menkir, A., Melake-Berhan, A., Ingelbrecht, I. \& Adepoju, A. (2004). Grouping of tropical mid-altitude maize inbred lines on the basis of yield data and molecular markers. Theoretical and Applied Genetics, 108(8), 1582-1590.

Meseka, S. K., Menkir, A., Ibrahim, A. E. S \& Ajala, S. O. (2013). Genetic analysis of maize inbred lines for tolerance to drought and low nitrogen. Jonares, 1, 29-36.

Museck, J. T \& Duser, D. A. (1980). Irrigated corn yield response to water. Transactions of the ASAE. St. Joseph, 23, 92-1040.

Ohland, R. A. A., Souza, L. C. F., Hernani, L. C., Marchetti, M. E \& Gonçalves, M. C. (2005). Culturas de cobertura do solo e adubação nitrogenada no milho em plantio direto. Ciência e Agrotecnologia, 29(3), 538-544.

Oishi, M. Y. \& Bewley, J. D. (1990). Distinction between the responses of developing maize kernels to fluridone and desiccation in relation to germinability, $\alpha-$ amylase activity, and abscisic acid content. Plant Physiology, 94(2), 592-598.

Oliveira Gondim, T. C., Rocha, V. S., Santos, M. M \& Miranda, G. V. (2006). Avaliação da qualidade fisiológica de sementes de milho-crioulo sob estresse causado por baixo nível de nitrogênio. Revista Ceres, 53(307), 413-417.

Pagano, A., Forti, C., Gualtieri, C., Balestrazzi, A., Macovei, A. (2019). Oxidative Stress and Antioxidant Defense in Germinating Seeds. A Q\&A Session. In: Hasanuzzaman, M., Fotopoulos, V., Nahar, K., Fujita, M. Reactive Oxygen, Nitrogen and Sulfur Species in Plants: Production, Metabolism, Signaling and Defense Mechanisms.

Pereira, L. M., Pereira, E. M., Revolti, L. T. M., Zingaretti, S. M \& Môro, G. V. (2015). Qualidade de semente, índice de conteúdo de clorofila e teor nitrogênio foliar em milho inoculado com Azospirillum brasilense. Ciência Agronômica, 46(3).

Pérez-Rodriguez, J. L., Escriba, R. C. R., González, L., Olmedo, J. L. G. \& Martínez-Montero, M. E. (2017). Effect of desiccation on physiological and biochemical indicators associated with the germination and vigor of cryopreserved seeds of Nicotiana tabacum L. cv. Sancti Spíritus 96 . In Vitro Cellular \& Developmental Biology - Plant, 53(1), 440-448.

Prazeres, C. S. \& Coelho, C. M. M. (2016). Heterose para qualidade fisiológica de sementes na obtenção de híbridos de milho. Revista Brasileira de milho e sorgo, 15(1), 124-133.

Riedell, W. E., Pikul JR., J. L., Jaradat, A. A \& Schumache, T. E. (2009). Crop Rotation and Nitrogen Input Effects on Soil Fertility, Maize Mineral Nutrition, Yield, and Seed Composition. Agronomy Journal, 101, 870-879.

Rodrigues, F., Von Pinho, R.G., Alburquerque, C.J.B., Faria Filho, E.M. \& Goulart, J.C. (2009). Capacidade de combinação entre linhagens de milho visando à produção de milho verde. Bragantia, 68(1), 75-84.

Santos, J. P. (2006). Controle de pragas durante o armazenamento de milho. Embrapa Milho e Sorgo-Circular Técnica 84. Sete Lagoas-MG: Embrapa, 20p.

Sawazaki, E., Paterniani, M. E. A. G. Z., Castro, J. L., Gallo P. B., Galvão, J. C. C. \& Saes, L. A. (2000). Potencial de linhagens de populações locais de milho pipoca para síntese de híbridos. Bragantia, 59(2), 143-151.

Schimildt, E. R., Nascimento, A. L., Cruz, C. D \& Oliveira, J. A. R. (2011). Avaliação de metodologias de adaptabilidade e estabilidade de cultivares milho. Acta Scientiarum. Agronomy, 33(1), 51-58.

Sentelhas, P. C., Faria, R. T., Chaves, M. O \& Hoogenbom, G. (2001). Evaluation of the WGEN and SIMMETEO weather generators for the brazilian tropics and subtropics, using crop simulation models. Revista Brasileira de Agrometeorologia, 9(2), 357-376.

Soares, M. O., Miranda, G. V., Guimarães, L. J. M., Marriel, I. E \& Guimarães, C. T. (2011). Parâmetros genéticos de uma população de milho em níveis contrastantes de nitrogênio. Revista Ciência Agronômica, 42(1), 168-174.

Souza, E. J., Cunha, F. F., Magalhães, T. R \& Santos, O. F. (2016). Eficiência do uso da água pelo milho doce em diferentes lâminas de irrigação e adubação nitrogenada em cobertura. Revista Brasileira de Agricultura Irrigada, 10(4), 750 - 757.

Souza, T. M., Bernd, L. P., Okumura, R. S., Takahashi, H. W., Ono, E. Y. S \& Hirooka, E. Y. (2016). Nitrogen fertilization effect on chemical composition and contamination by fungal-fumonisin of maize kernel. Revista Brasileira de Ciências Agrárias, 11(3), 218-223.

Steffen, W \& Richardson, K \& Rockström, J \& Cornell, S. E \& Fetzer, I \& Bennett, E. M \& Folke, C. (2015). Planetary boundaries: Guiding human development on a changing planet. Science, 347(6223).

Thiraporn, R., Feil, B \& Stamp, P. (1992). Effect of nitrogen fertilization on grain yield and accumulation of nitrogen, phosphorus and potassium in the grains of tropical maize. Journal of Agronomy and Crop Science, 169(12), 9-16.

Tsai, C. Y., Dweikat, I., Huber, D.M. \& Warren, H.L. (1992). Interrelationship of nitrogen nutrition with maize (Zea mays) grain yield, nitrogen use efficiency and grain quality. Journal of the Science of Food and Agriculture, 58(1), 1-8.

Tsai, C. Y., Warren, H. L., Huber, D. M \& Bressan, R. A. (1983). Interactions between the kernel N sink, grain yield and protein nutritional quality of maize. Journal of the Science of Food and Agriculture, 34(3), 255-263.

Uribelarrea, M., Below, F. E \& Moose, S. P. (2004). Grain composition and productivity of maize hybrids derived from the Illinois protein strains in response to variable nitrogen supply. Crop science, 44(5), 1593-1600.

Von Wirén, N., Gazzarrini, S., Gojon, A. \& Frommer, W. B. (2000). The molecular physiology of ammonium uptake and retrieval. Current opinion in plant biology, 3(3), 254-261. 
Research, Society and Development, v. 10, n. 9, e23410917144, 2021

(CC BY 4.0) | ISSN 2525-3409 | DOI: http://dx.doi.org/10.33448/rsd-v10i9.17144

White, C. N., Proebsting, W. M., Hedden, P. \& Rivin, C. J. (2000). Gibberellins and seed development in maize. I. Evidence that gibberellin/abscisic acid balance governs germination versus maturation pathways. Plant Physiology, 122(4), 1081-1088.

Zamboni, A., Astolfi, S., Zuchi, S., Pii, Y., Guardini, K., Tononi, P. \& Varanini, Z. (2014). Nitrate induction triggers different transcriptional changes in a high and a low nitrogen use efficiency maize inbred line. Journal of Integrative Plant Biology, 56(11), 1080-1094.

Zucareli, C., Panoff, B., Portugal, G \& Fonseca, I. N. C. (2012). Doses e épocas de aplicação de nitrogênio em cobertura na qualidade fisiológica de sementes de milho doce. Revista Brasileira de Sementes, 34(3), 480-487. 